\title{
PADRÕES DE CIRCULAÇÃO EM SUPERFÍCIE E EM 500 HPA NA AMÉRICA DO SUL E EVENTOS DE ANOMALIAS POSITIVAS DE PRECIPITAÇÃO NO ESTADO DE MINAS GERAIS DURANTE O MÊS DE DEZEMBRO DE 2011
}

\author{
GUSTAVO CARLOS JUAN ESCOBAR \\ Instituto Nacional de Pesquisas Espaciais, Centro de Previsão de Tempo e Esudos Climáticos (INPE/ \\ CPTEC), Cachoeira Paulista, SP, Brasil \\ gustavo.escobar@cptec.inpe.br
}

Recebido Outubro de 2012 - Aceito Julho de 2013

\begin{abstract}
RESUMO
O presente trabalho apresenta uma classificação dos campos de circulação atmosférica em superfície e $500 \mathrm{hPa}$ sobre a América do Sul durante o mês de dezembro, com o intuito de identificar os principais padrões sinóticos que influenciam o tempo na Região Sudeste do Brasil, principalmente no Estado de Minas Gerais (MG). A metodologia utilizada foi a técnica de Análise de Componentes Principais rotacionadas aplicada à série de reanálises do NCEP para o período 1986-2011. O intuito final desta classificação foi determinar os padrões de circulação predominantes durante o mês de dezembro de 2011, que estiveram relacionados com a ocorrência de precipitações anômalas no Estado de MG. Os resultados obtidos para o período 1986-2011 destacam seis padrões de sequências principais (PSP) de circulação em superfície e quatro padrões de altitude que representam $72,8 \%$ e $94 \%$ dos casos analisados, respectivamente. Em superfície houve três padrões de circulação principais associados com maior probabilidade de ocorrência de chuva sobre o Estado MG; um deles associado com uma frente fria no sul da Região Sudeste (PSP2-Sup), e outros dois (PSP3-Sup e PSP5-Sup) relacionados com uma configuração de bloqueio de tipo "dipolo" no oceano Atlântico determinado por um anticiclone localizado em torno de $50^{\circ} \mathrm{W}, 45^{\circ} \mathrm{S}$ e por uma baixa posicionado ao norte do anticiclone em torno de $25^{\circ} \mathrm{S}$. Em $500 \mathrm{hPa}$ houve dois padrões de circulação associados com a ocorrência de chuva significativa sobre o Estado mineiro que se refletiram nos campos obtidos em superfície; um deles associado ao avanço de um sistema frontal frio (PSP2-500) e o outro relacionado com uma situação de bloqueio de tipo "dipolo" no oceano Atlântico (PSP4-500). As chuvas anômalas registradas durante dezembro de 2011 estiveram associadas diretamente com a atuação dos padrões de circulação PSP3-Sup e PSP4500, sendo que ambos os modelos estiveram relacionados com a atuação de episódios de Zona de Convergência do Atlântico Sul (ZCAS).
\end{abstract}

Palavras chave: classificação sinótica, componentes principais, chuvas anômalas.

\begin{abstract}
CIRCULATION PATTERNS IN SURFACE AND 500 HPA OVER SOUTH AMERICA AND EVENTS OF POSITIVE PRECIPITATION ANOMALIES ON THE MINAS GERAIS STATE DURING DECEMBER OF 2011

This paper presents a classification of atmospheric circulation fields in surface and $500 \mathrm{hPa}$ over South America during the month of December, in order to identify the main synoptic patterns that influence the weather in the Southeast region of Brazil, especially in the state of Minas Gerais (MG). To this purpose, the Rotated Principal Component Analysis technique was applied to the NCEP reanalysis for the period 1986-2011. The principal aim of this classification was to determine the circulation patterns prevailing during the month of December 2011 related to the anomalous rainfall occurred in the State of Minas Gerais (MG). The results provide six circulation patterns in surface and four circulation patterns in altitude that are representative of about $72.8 \%$ and $94 \%$ of all the cases, respectively. Three main surface circulation patterns associated with higher probability of precipitation over the State of MG were found. One of them was associated with the advance
\end{abstract}


of a cold front that reaches the southern part of the Southeast region of Brazil (PSP2-Sup), and two others (PSP3-Sup and PSP5-Sup) related to a "dipole" blocking configuration over Atlantic ocean determined by an anticyclone located around $50^{\circ} \mathrm{W}, 45^{\circ} \mathrm{S}$ and a low positioned north of the anticyclone around $25^{\circ} \mathrm{S}$. At $500 \mathrm{hPa}$ two main circulation patterns were associated with the occurrence of significant precipitation over the State of MG reflecting the low level circulation; one associated with a cold front (PSP2-500) and another related to a "dipole" blocking situation over the Atlantic Ocean (PSP4-500). The anomalous rainfall observed during December 2011 were associated directly with the PSP3-Sup and PSP4-500 and both of them were related to the performance of South Atlantic Convergence Zone (SACZ) episodes.

Keywords: synoptic clasification, principal components, anomalous rainfall.

\section{INTRODUÇÃO}

Todos os anos a Região Sudeste do Brasil é atingida por chuvas intensas, que ocorrem principalmente no período de verão e como consequência disso causam desastres naturais, como deslizamentos de terras e enchentes, que trazem enormes prejuízos à população e em alguns casos perdas de vida humana. O início do período chuvoso de 2011/2012 no Brasil não foi diferente. As chuvas que atingiram os Estados de Minas Gerais (MG), Rio de Janeiro (RJ) e o Espírito Santo (ES) provocaram muitos impactos à população.

As chuvas mais intensas sobre o Sudeste do Brasil tiveram início no final de novembro e se intensificaram ao longo de dezembro de 2011, sendo que o Estado de MG foi uns dos mais castigados pelas chuvas intensas durante este mês. A Figura 1 mostra que as anomalias positivas de precipitação foram observadas sobre grande parte do Estado mineiro, sendo que as microrregiões mais afetadas pelas chuvas foram: Alto São Francisco, Belo Horizonte Metalúrgica, Rio Doce Mucuri, Sul Campo das Vertentes e a Zona da Mata Mineira. É possível observar (Figura 1) anomalias positivas de mais de $200 \mathrm{~mm}$ em várias localidades destas microrregiões. Segundo o Instituto Nacional de Meteorologia (INMET), em Belo Horizonte, registrou-se $710 \mathrm{~mm}$ de chuva ao longo do mês de dezembro, sendo que o valor climatológico é de $292 \mathrm{~mm}$.

Durante a estação chuvosa do Brasil, ou seja, aproximadamente entre os meses de outubro e abril, a Região Sudeste caracteriza-se pela presença de abundantes chuvas, devido principalmente ao sistema de monção da América do Sul (AS) (Veiga, 2000; Gan et al., 2004; Grimm et al., 2005; Vera et al., 2006). Nesta época do ano, o aquecimento radiativo da superfície se concentra nos subtrópicos, contribuindo para o desenvolvimento de atividade convectiva (Reboita et al, 2010). Dentre as principais forçantes dinâmicas que atuam durante o período chuvoso e contribuem para geração de abundantes chuvas, podem-se mencionar os transientes, como por exemplo, cavados, frentes frias e estacionárias no oceano, ciclones extratropicais e subtropicais em superfície e sistemas de altitude que geram forte divergência em altos níveis.
As frentes frias, nesta época do ano, atingem com menor frequência as áreas continentais das Regiões Sul e Sudeste já que apresentam um deslocamento mais zonal e marítimo (Andrade, 2005). Mas, em várias ocasiões, estes sistemas frontais ficam estacionários por mais de 3 dias e conseguem organizar um canal de umidade desde o oceano Atlântico até o interior do continente provocando chuvas intensas em parte das Regiões Sudeste, Centro-Oeste e Norte do Brasil, caracterizando-se o fenômeno de Zona de Convergência do Atlântico Sul (ZCAS)(Kousky, 1988; Kodama, 1992; Quadro, 1994; Carvalho et al., 2004).

A ZCAS é caracterizada por uma persistente banda de nebulosidade orientada no sentido noroeste-sudeste, que se estende desde a Amazônia até o Oceano Atlântico sudoeste, influenciando as precipitações desde o centro-sul da Região Norte até o norte do Paraná, incluindo a totalidade das Regiões Centro-Oeste e Sudeste e o oeste da Bahia. Escobar e Carvalho (2005) analisaram a circulação atmosférica em superfície associada com eventos de ZCAS mediante a técnica de Análises

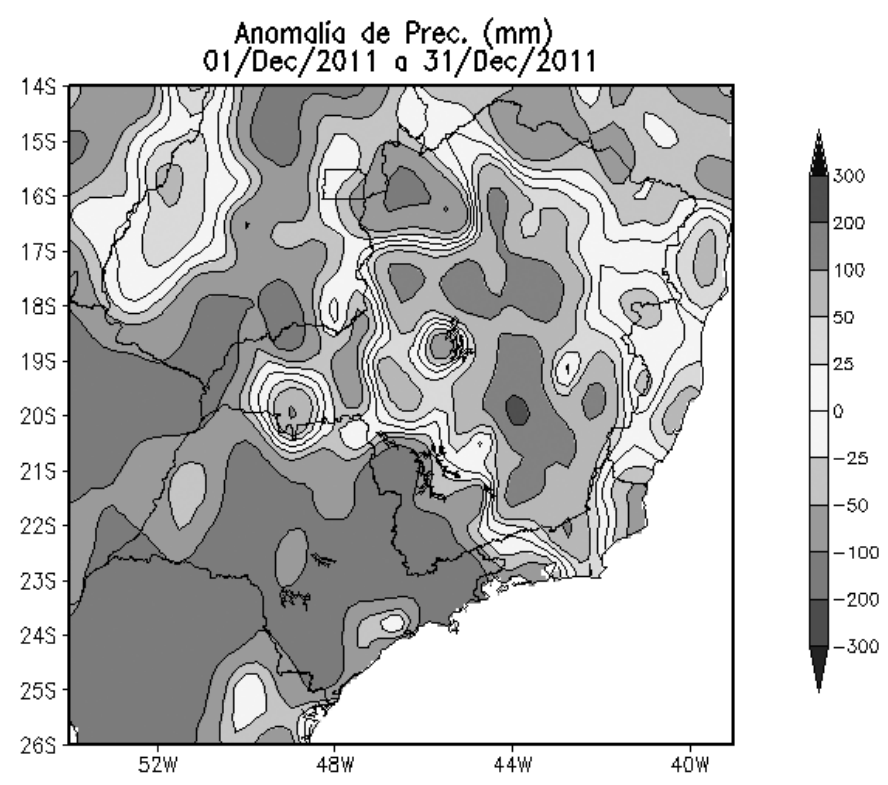

Figura 1 - Anomalias de precipitação ocorridas durante o mês de dezembro de 2011. Fontes de dados: CPTEC/INPE - INMET CEMIG/SIMGE/MG - SEAG/ES. 
de Componentes Principais (ACP). Eles encontraram três modos principais de circulação atmosférica em superfície; o primeiro associado a eventos ciclogenéticos no oceano Atlântico Sul, o segundo modo relacionado ao avanço de uma frente fria clássica sobre o Sudeste do Brasil e o terceiro associado à presença de um cavado no oceano Atlântico na altura do Sudeste do Brasil.

Existem diversos trabalhos relacionados com a dinâmica atmosférica e o comportamento espacial da precipitação sobre o Estado de MG.

Vianello e Maia (1986) fizeram um estudo preliminar sobre as principais configurações atmosféricas predominantes sobre a América do Sul e sua relação com a variabilidade espacial e sazonal da chuva sobre o Estado de MG. Os resultados obtidos neste estudo mostraram a importância do Anticiclone Subtropical do Atlântico Sul (ASAS) durante o verão, contribuindo para advectar ar úmido tropical através da circulação de quadrante norte. Os autores também mencionam a importância da Alta da Bolívia que durante o verão gera um escoamento meridional e contribui para gerar mecanismos ascendentes sobre a maior parte da Bacia do São Francisco. Os autores também ressaltam a importância da topografia como fator fundamental para induzir chuvas localizadas ou intensificar as linhas de instabilidades que frequentam as áreas com relevos acentuados.

Abreu (1999) analisou a influência do fenômeno de ZCAS e sua relação com a ocorrência de chuvas no Estado de MG, descrevendo os principais fatores para a configuração deste fenômeno. Segundo a autora, quatro fatores são indispensáveis para a configuração de ZCAS; presença de instabilidade tropical formada pelo forte aquecimento continental, sistema frontal no oceano organizando a convecção amazônica no sentido noroeste-sudeste, jato de baixos níveis direcionado para o Sudeste do Brasil por causa da presença dos Andes que desvia os alísios e a advecção de umidade proveniente da região amazônica mediante a atuação do jato de baixos níveis.

Moreira e Abreu (2002) estudaram a distribuição espacial da precipitação sobre a região metropolitana de Belo Horizonte associada com a topografia local. Os resultados encontrados por estes autores mostraram a importância do fator topográfico na ocorrência de chuvas intensas entre os meses de setembro e janeiro.

Até o presente, a maioria dos trabalhos associados com chuvas intensas anômalas sobre o Estado de MG, é baseada em análises individuais de casos específicos, que conseguem identificar as características preponderantes da circulação atmosférica. Portanto, este trabalho tem como objetivo elaborar uma climatologia da circulação atmosférica em superfície e $500 \mathrm{hPa}$ para o mês de dezembro (1986-2011) e determinar os principais padrões de circulação nestes níveis associados às anomalias positivas de precipitação ocorridas no Estado de Minas Gerais (MG) durante o mês de dezembro de 2011. O intuito final deste trabalho é determinar se as chuvas anômalas observadas neste período podem ser atribuídas com algum padrão de circulação específico.

Na seção 2 são apresentados os dados e a metodologia utilizada, a seção 3 mostra os resultados da classificação da circulação atmosférica e a análise da circulação em superfície e $500 \mathrm{hPa}$ associada às chuvas intensas ocorridas em MG. A seção 4 apresenta uma síntese dos principais resultados obtidos neste trabalho.

\section{MATERIAL E MÉTODOS}

\subsection{Dados}

Para a análise dos campos de circulação em superfície e altitude foram usados os dados diários de pressão ao nível médio do mar (SLP) e dados de geopotencial (hgt) em $500 \mathrm{hPa}$ para o mês de dezembro, provenientes da reanálise do NCEP/ NCAR (National Center for Environmental Prediction/National Center for Atmospheric Research) para o período 1986 a 2011 (Kalnay et al., 1996).

\subsection{Análise de Componentes Principais (ACP)}

\subsubsection{Classificação sinótica}

Um dos principais objetivos da climatologia sinótica é compreender a relação entre a circulação atmosférica e as condições ambientais em superfície mediante a utilização de métodos objetivos de classificação. No início do século vinte, todos os métodos utilizados para classificar padrões de circulação atmosférica eram manuais e em consequência subjetivos. A partir da década de sessenta, estes métodos subjetivos têm sido substituídos por técnicas objetivas, como por exemplo, a metodologia de correlação de Lund (1963). Porém, existem métodos ainda mais objetivos e matematicamente eficientes que são derivados da técnica do autovetor (Preisendorfer, 1988).

A Análise de Componentes Principais ( $\mathrm{ACP}$ ) pertence ao modelo de classificação derivado da técnica do autovetor e tem sido utilizada particularmente em pesquisa relacionada com a climatologia sinótica. Yarnal (1993) apresenta uma completa descrição da técnica de ACP e suas aplicações em variáveis meteorológicas e climatológicas.

Existem dois tipos de ACP utilizados para analisar a variável observada, tanto no espaço quanto no tempo. O primeiro chamado Modo-S está relacionado com a análise de séries temporais correspondentes a pontos no espaço. Isto significa que a variável estatística analisada corresponde a séries temporais de uma variável meteorológica que pode ser considerada contínua no espaço e no tempo. Por outro lado, o 
Modo-T pode ser aplicado para classificar campos atmosféricos espaciais (Compagnucci e Salles, 1997; Escobar e Bischoff, 1999; Escobar et. al, 2004; Escobar, 2007). Segundo Richman (1983), o Modo-T é uma ferramenta muito útil para sintetizar e reproduzir padrões de circulações, quantificando sua frequência e mostrando os períodos de tempo neles dominantes.

Para a caracterização dos padrões de circulação em superfície e em $500 \mathrm{hPa}$, correspondentes ao mês de dezembro, foi realizada uma classificação sinótica das sequências de campos de pressão ao nível do mar e de altura geopotencial em $500 \mathrm{hPa}$. A sequência foi formada pelo campo de circulação correspondentes aos dias $-2,-1$ e 0 . A metodologia utilizada foi a ACP com uma matriz de correlação em Modo - T (Green, 1978; Richman, 1986).

Os Padrões de Sequências Principais (PSP) foram obtidos usando a aproximação de Compagnucci et. al (2001). Nesta aplicação as variáveis são sequências de padrões espaciais de pressão ao nível do mar e de altura geopotencial em 500 hPa e a matriz de correlação representa a correlação entre sequências. Esta aproximação é considerada como uma extensão da tradicional ACP, com uma matriz de correlação em Modo-T, cujo objetivo principal é obter a evolução dos principais modos dominantes de circulação, que permitam analisar a trajetória e o comportamento dos sistemas sinóticos sobre determinadas áreas.

Após a aplicação desta aproximação foi feita a rotação Varimax. A rotação das componentes principais tem como principal objetivo redistribuir a variância total dos dados utilizados com o intuito de facilitar o significado físico das componentes obtidas (Richman, 1986). Para a determinação do número de componentes rotacionadas utilizou-se a regra do autovalor 1.0 (Richman et. al, 1992).

Para a determinação das sequências de situações meteorológicas altamente correlacionadas com os PSP foram utilizadas as séries temporais de factor loadings (componentes de peso) que representam as correlações entre cada variável (situação meteorológica real) e cada componente principal

\begin{tabular}{|l|c|}
\hline CPs & VAR. (\%) / CUM. VAR (\%) \\
\hline 1 & 23,4 / 23,4 \\
\hline 2 & $22,0 / 45,4$ \\
\hline 3 & 11,5 / 56,9 \\
\hline 4 & $8,3 / 65,2$ \\
\hline 5 & $4,0 / 69,2$ \\
\hline 6 & $3,6 / 72,8$ \\
\hline
\end{tabular}

Tabela 1 - Porcentagens da variância explicada e da variância acumulada pelos seis primeiros PSP de superfície durante o mês de dezembro.
(Richman, 1986). A análise da série de factor loadings permite determinar a representatividade das componentes principais como situações sinóticas reais, valores próximos a 1 representam sequências de situações meteorológicas similares às sequências das componentes principais obtidas (Harman, 1976; Cattel, 1978).

\subsubsection{Determinação dos padrões de circulação atmosférica em superfície e $500 \mathrm{hPa}$ predominantes durante 0 mês de dezembro de 2011}

Os resultados obtidos da elaboração da classificação da circulação atmosférica do mês de dezembro permitem identificar os principais padrões de circulação em superfície e $500 \mathrm{hPa}$ que caracterizam o tempo e clima da Região Sudeste do Brasil. Esses padrões de circulação predominantes variam ao longo do ano e em função desta variabilidade interanual é possível explicar eventos anômalos de chuva e/ou temperatura sobre determinadas áreas desta Região. A variabilidade interanual destes padrões de circulação pode ser determinada através do cálculo da variância explicada através da PSP para cada um dos 26 anos analisados. Esta variância explicada foi calculada através das séries temporais de factor loadings (Richman, 1986). Desta maneira é possível identificar quais dos PSP obtidos desta classificação tiveram maior contribuição na ocorrência de chuvas intensas no Estado de MG durante o mês de dezembro de 2011.

\section{RESULTADOS}

\subsection{Classificação sinótica do mês de dezembro}

\subsubsection{Pressão ao nível do mar}

A aplicação da ACP identificou seis PSP em superfície nos dados de pressão atmosférica que explicaram 72,8\% da variância total no mês de dezembro. A Tabela 1 mostra as porcentagens da variância explicada e as porcentagens da variância acumulada através da PSP. Nota-se que os três primeiros PSP explicaram mais dos $50 \%$ da variância total explicada para o mês de dezembro.

As primeiras cinco séries de fator loadings mostraram valores maiores que 0,7 (Figuras não apresentada). Isto significa que os PSP e as situações sinóticas reais têm configurações similares. O PSP6 não foi considerado já que a série de factor loadings mostrou valores inferiores a 0,5 .

Nas Figuras 2 a 6 observam-se os cinco PSP (parte superior) e os casos observados altamente correlacionados (parte inferior) com eles. O primeiro PSP (Figura 1, parte superior), PSP1-Sup, mostra uma configuração semelhante ao campo médio de verão (vide Figura 3C, 1a, Satyamurty et al, 1998). Nota-se uma área de baixa pressão alongada, se estendendo a 

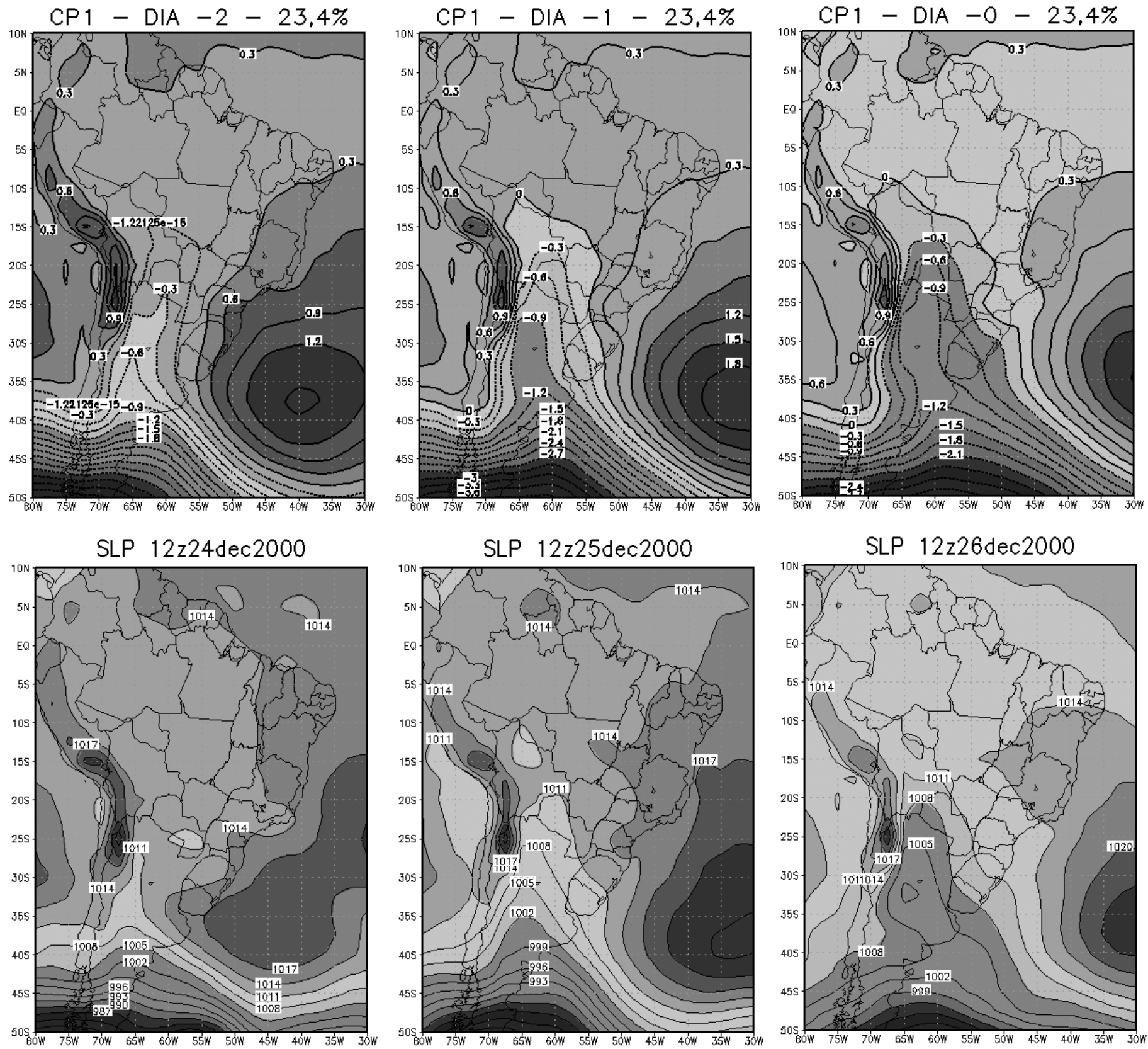

Figura 2 - Primeira Sequência de Componentes Principais (PSP1-Sup) (parte superior) e um caso de pressão em superfície altamente correlacionado $(24 / 12 / 00-26 / 12 / 00)$ (parte inferior).

leste dos Andes desde o sul da Argentina até o sul da Bolívia. Esta ampla área alongada de baixa pressão está associada ao acoplamento da Baixa do Noroeste da Argentina (BNOA) com um sistema transiente (frente fria ou cavado) mais ao sul. $\mathrm{O}$ caso real (Figura 2, parte inferior) mostra o deslocamento do sistema transiente de forma zonal ao sul do paralelo $40^{\circ} \mathrm{S}$ e a formação da BNOA. Durante o último dia da sequência (26/12/00), o transiente de latitudes médias se acopla e interage com a BNOA que se localiza aproximadamente na altura da Província de Mendoza (Argentina). O PSP1-Sup também mostra a presença do Anticiclone Subtropical do Atlântico Sul (ASAS) centrado aproximadamente entre os paralelos $35^{\circ} \mathrm{S}$ e $40^{\circ} \mathrm{S}$ e com um lento deslocamento para leste. Sobre a Região Sudeste do Brasil é possível observar a influência da borda noroeste do ASAS que atua como um inibidor dinâmico do mecanismo de levantamento, principalmente sobre os Estado do RJ, MG e o ES. No entanto, a presença do ASAS contribui para advectar ar tropical quente e úmido mediante a circulação de quadrante norte, leste e nordeste, sendo este o principal responsável pelas chuvas de verão (Vianello et. al, 1986). Em certas ocasiões pode 

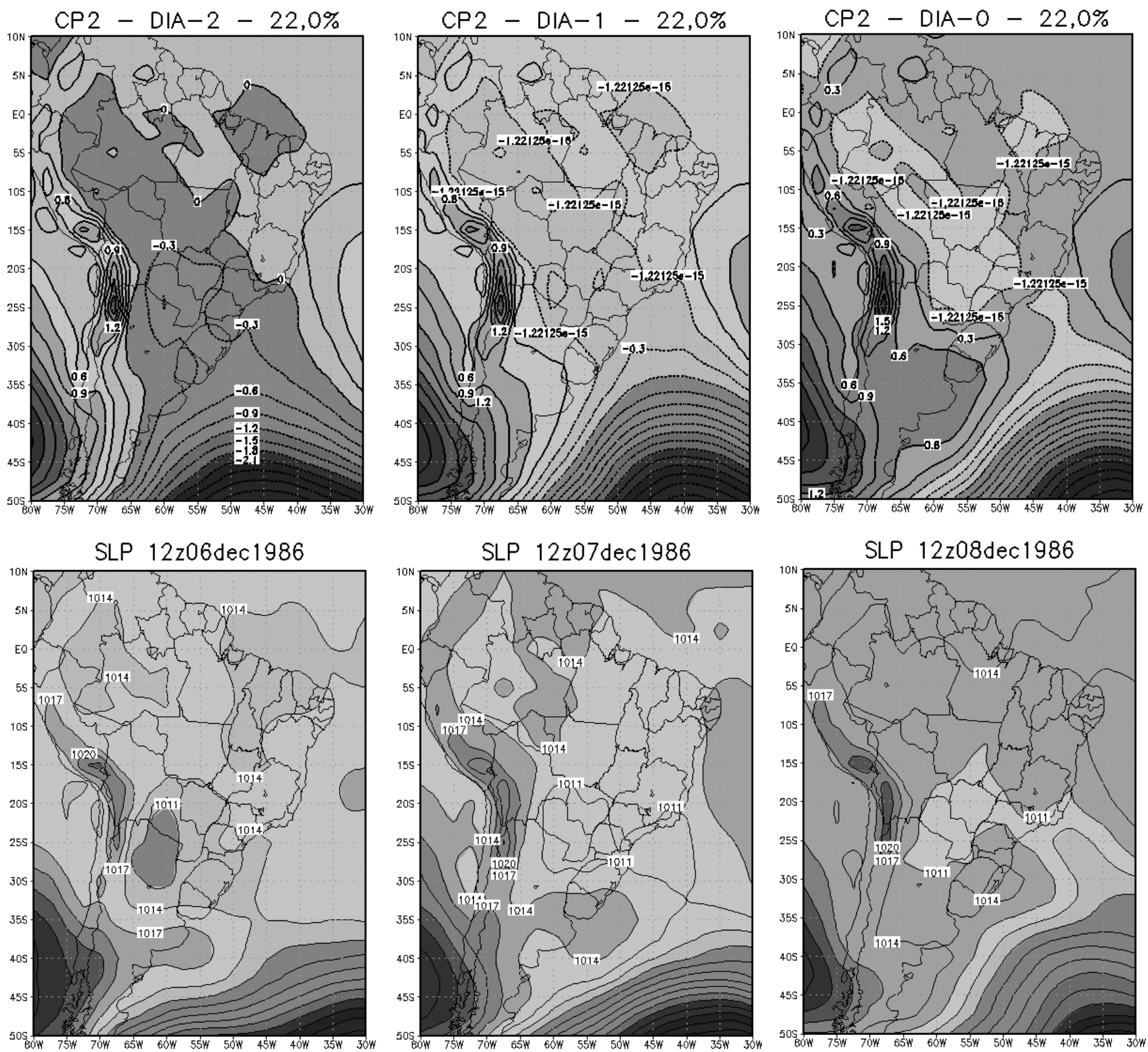

Figura 3 - Segunda Sequência de Componentes Principais (PSP2-Sup) (parte superior) e um caso de pressão em superfície altamente correlacionado $(06 / 12 / 86-08 / 12 / 86)$ (parte inferior).

aparecer um cavado invertido orientado zonalmente na borde ocidental do ASAS, na altura do Estado de SP, como pode-se observar no último dia da sequência (Figura 2). Este sistema de baixa pressão em superfície pode aparecer quando os ventos de noroeste descem a serra do Mar.

O segundo PSP (Figura 3, parte superior), PSP2-Sup, mostra o deslocamento de uma típica frente fria que no dia-2 encontra-se no sul do Rio Grande do Sul (RS) e no dia-0 chega ao sul do Estado do RJ. O avanço deste sistema acaba instabilizando o tempo sobre boa parte da Região Sul do Brasil e em parte do Centro-Oeste e Sudeste. Em certas ocasiões, este sistema frontal fica estacionário por vários dias e organiza um canal de umidade se estendendo desde o oceano Atlântico até o sul da região amazônica. Assim fica configurado um episódio de ZCAS que provoca chuvas significativas sobre parte das regiões Sudeste, Centro-Oeste e Norte do Brasil. Este padrão sinótico associado com a ZCAS foi encontrado por Escobar e Carvalho (2005), que fizeram uma classificação sinótica com uma amostra 

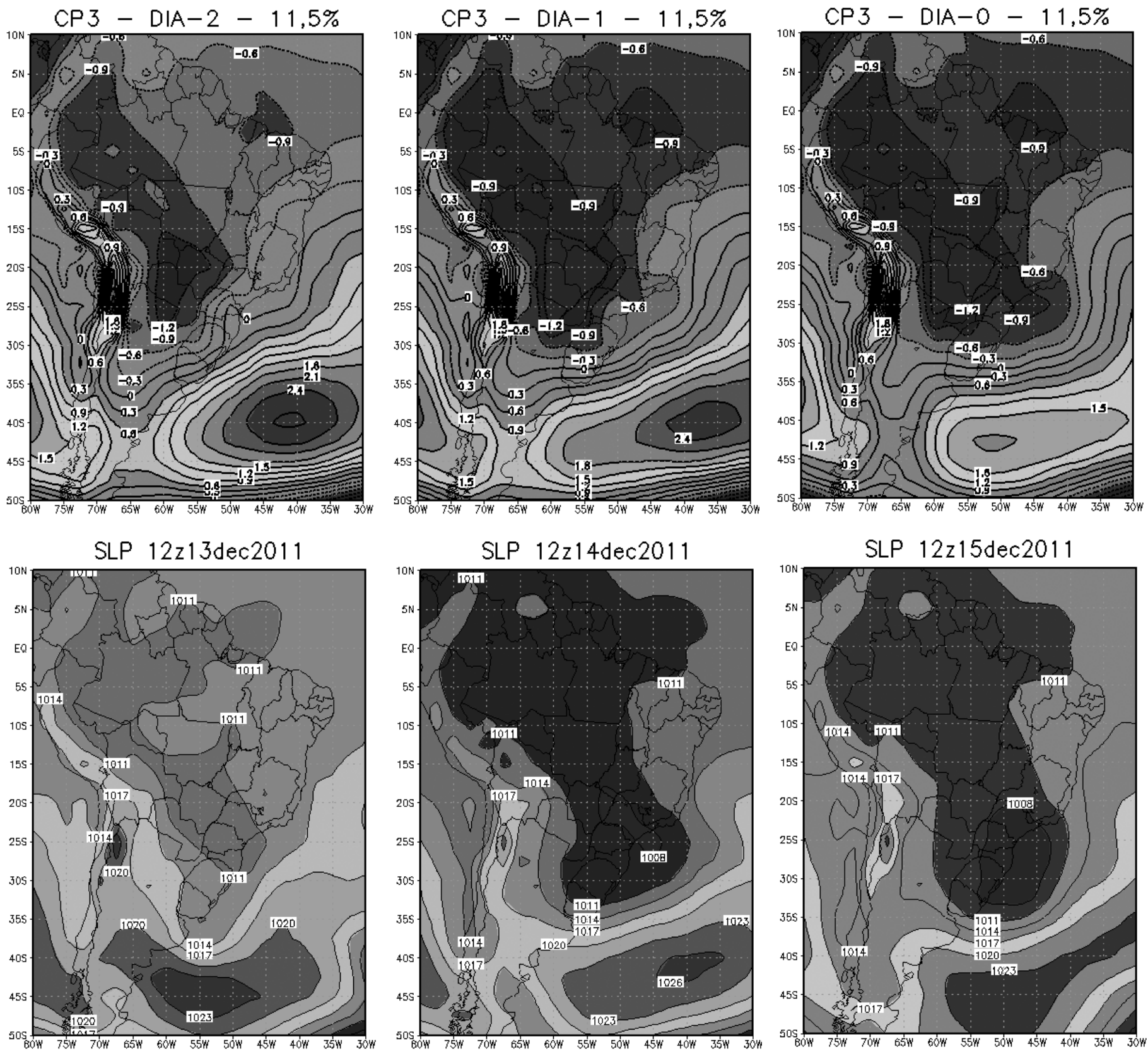

Figura 4- Terceira Sequência de Componentes Principais (PSP3-Sup) (parte superior) e um caso de pressão em superfície altamente correlacionado $(13 / 12 / 11$ - 15/12/11) (parte inferior).

de mais de 80 casos de ZCAS. Com esta configuração de ZCAS as chuvas significativas podem atingir principalmente o sul, o oeste e centro do Estado de MG (Escobar e Carvalho, 2005).

O terceiro PSP (Figura 4, parte superior), PSP3-Sup, apresenta uma ampla área de baixa pressão aproximadamente entre o nordeste da Argentina, Paraguai e o Estado de Mato Grosso do Sul (MS) se estendendo em direção ao oceano, entre os paralelos $25^{\circ} \mathrm{S}$ e $35^{\circ} \mathrm{S}$. Simultaneamente, no oceano Atlântico, observa-se um anticiclone quase estacionário, com deslocamento para oeste, principalmente entre os paralelos $42^{\circ} \mathrm{S}$ e $50^{\circ} \mathrm{W}$ no dia 0 . Este sistema de alta pressão está associado com o ASAS que se localiza um pouco mais ao sul da sua posição climatológica. Ambos os sistemas de pressão, tanto a ampla área de baixa quanto a alta oceânica do Atlântico determinam um índice de circulação zonal baixo, impedindo que os transientes avancem para latitudes mais baixas. A experiência operacional mostra que este padrão de circulação em superfície está frequentemente associado com a presença de ciclones extratropicais fracos ou, em várias ocasiões 
ciclones subtropicais que atuam no oceano entre os Estados de Santa Catarina (SC) e RJ. A Figura 4 (parte superior) mostra um caso real altamente correlacionado com este PSP, na qual é possível observar, no dia 15/12/2011, um ciclone de $1008 \mathrm{hPa}$ bastante amplo, localizado a leste da Região Sul do Brasil. Esta área ciclônica oceânica corresponde a uma região ciclogenética preferencial na América do Sul durante o verão (Sinclair, 1995; Hoskins e Hodges, 2005; Reboita et al 2010; Guia, 2010). Em várias oportunidades, este sistema de baixa pressão pode estar associado a episódios de ZCAS (Carvalho et al 2004; Escobar e Carvalho, 2005). Nestes casos, o sistema de baixa pressão advecta ar quente e úmido proveniente da região amazônica determinando uma forte convergência de massa e umidade sobre toda a Região Sudeste do Brasil (Escobar e Carvalho, 2005). Esta importante forçante dinâmica, combinada com a presença de uma massa úmida e quente, transforma-se em um dos principais mecanismos de levantamento e em consequência de geração de chuvas volumosas sobre o Estado de MG (Abeu, 1999).
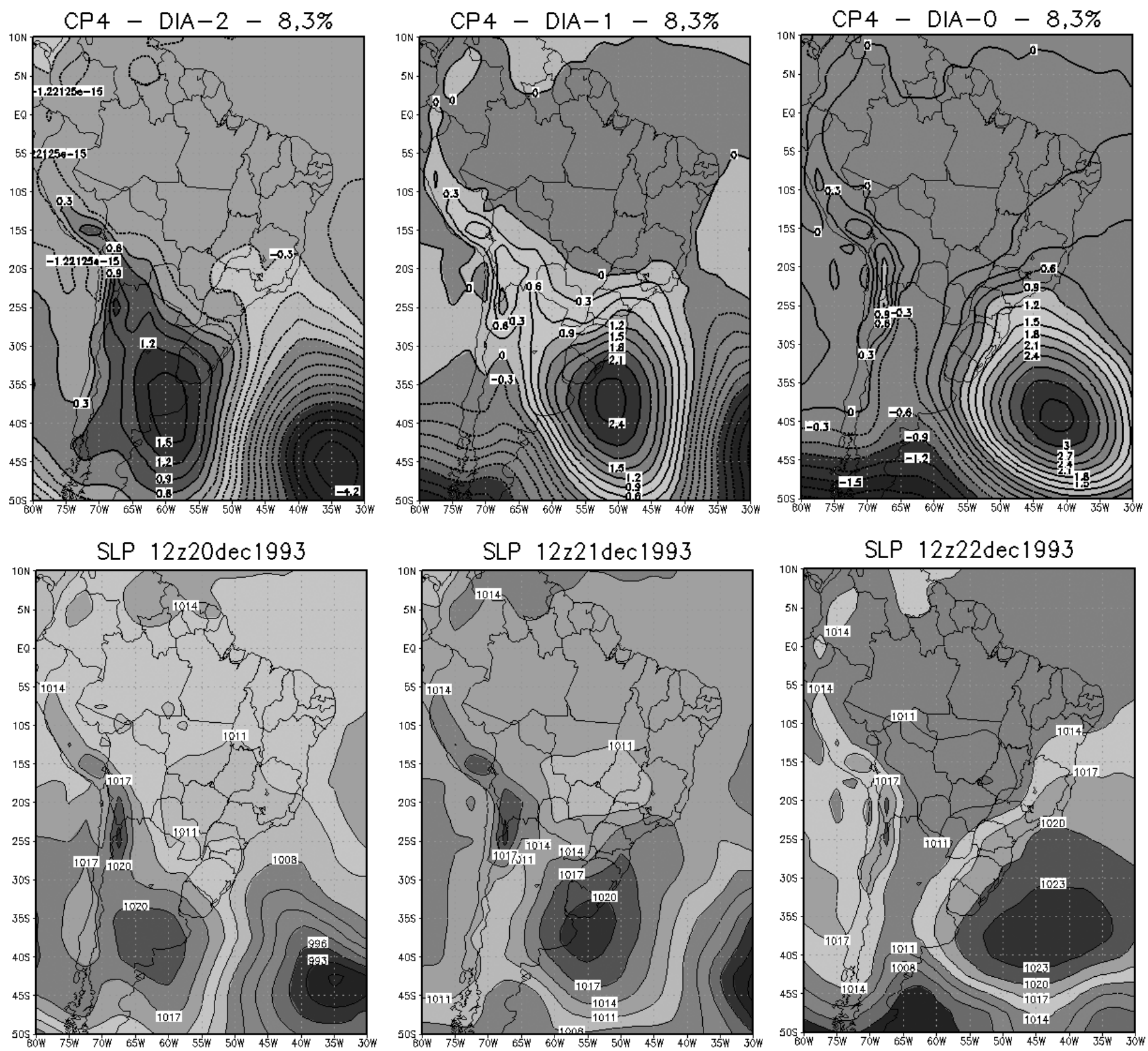

Figura 5 - Quarta Sequência de Componentes Principais (PSP4-Sup) (pare superior) e um caso de pressão em superfície altamente correlacionado $(20 / 12 / 93-22 / 12 / 93)$ (parte inferior). 
O quarto PSP (Figura 5, parte superior), PSP4-Sup, apresenta um modelo de circulação associado com a entrada de uma frente fria sobre a Região Sudeste do Brasil. Em relação ao PSP2-Sup, que também se relaciona com o deslocamento de um sistema frontal, a diferença principal é a posição e a intensidade do anticiclone pós-frontal.

O PSP4-Sup mostra um anticiclone pós-frontal intenso que se desloca de maneira quase zonal, porém atingindo a porção centro-sul da Região Sudeste. A Figura 5 (parte inferior) apresenta um caso real altamente correlacionado com este padrão. Nota-se que a frente fria chega ao Estado de SP no dia -2, avançando para os Estados do RJ, MG e ES no dia -1 e ficando no oceano Atlântico no dia 0 . É importante ressaltar que este padrão sinótico é menos frequente em relação aos descritos anteriormente, já que explica o 8,3\% da variância total dos casos analisados. Este modelo de circulação em superfície também pode associar-se com chuvas intensas na região metropolitana do RJ, já que padrões de circulação em superfície similares

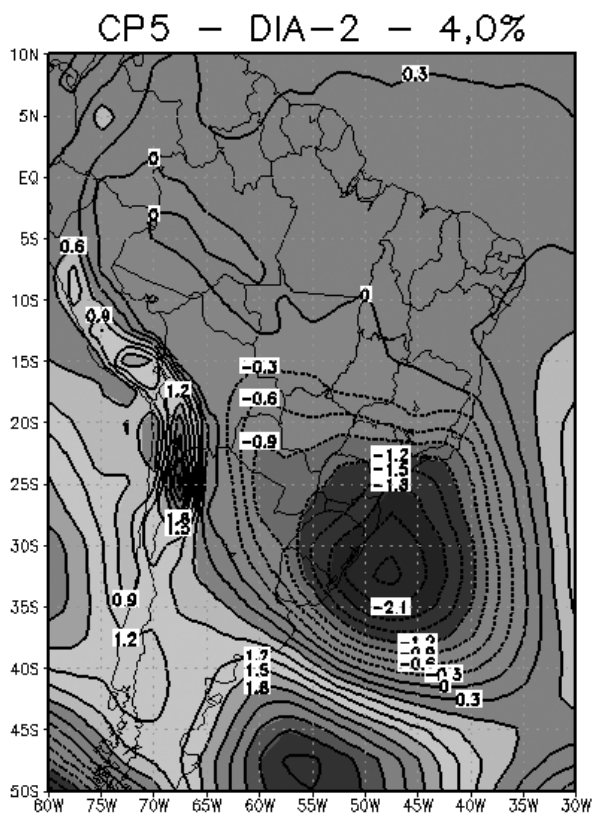

SLP $12 z 16 \operatorname{dec} 2011$

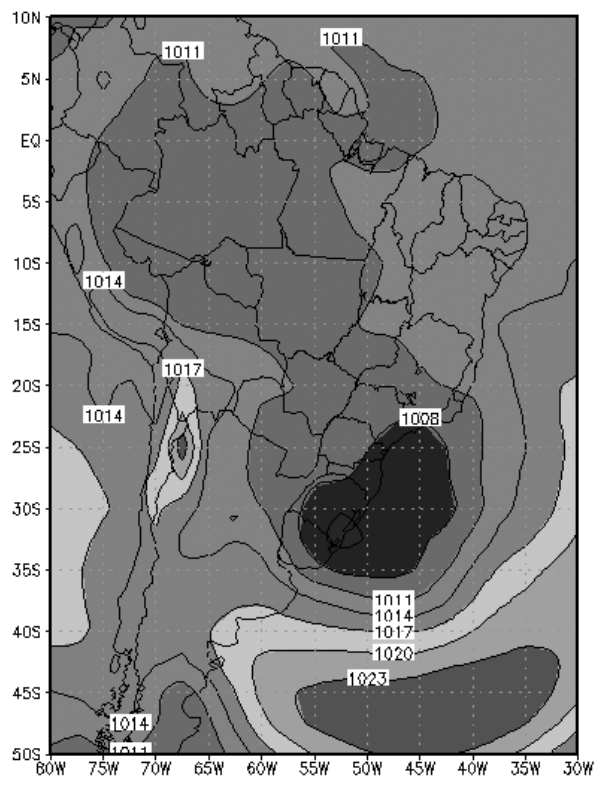

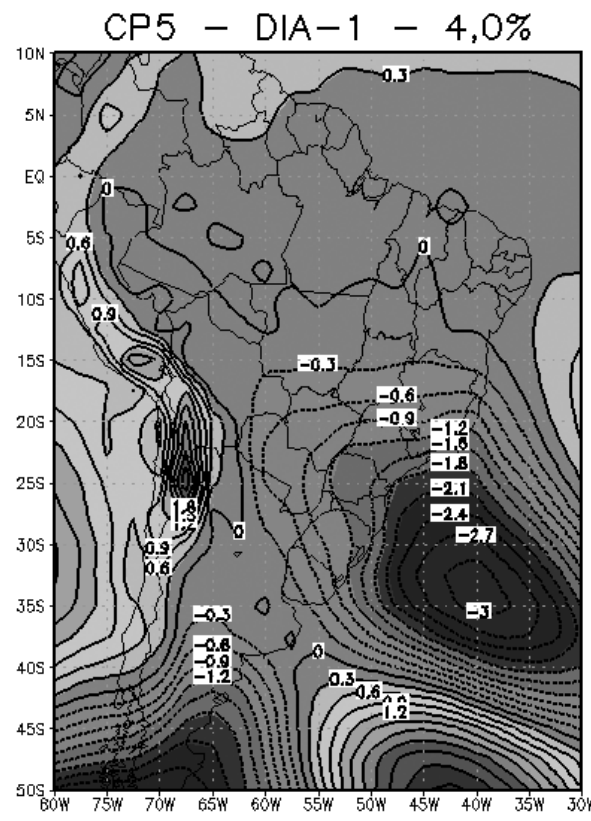
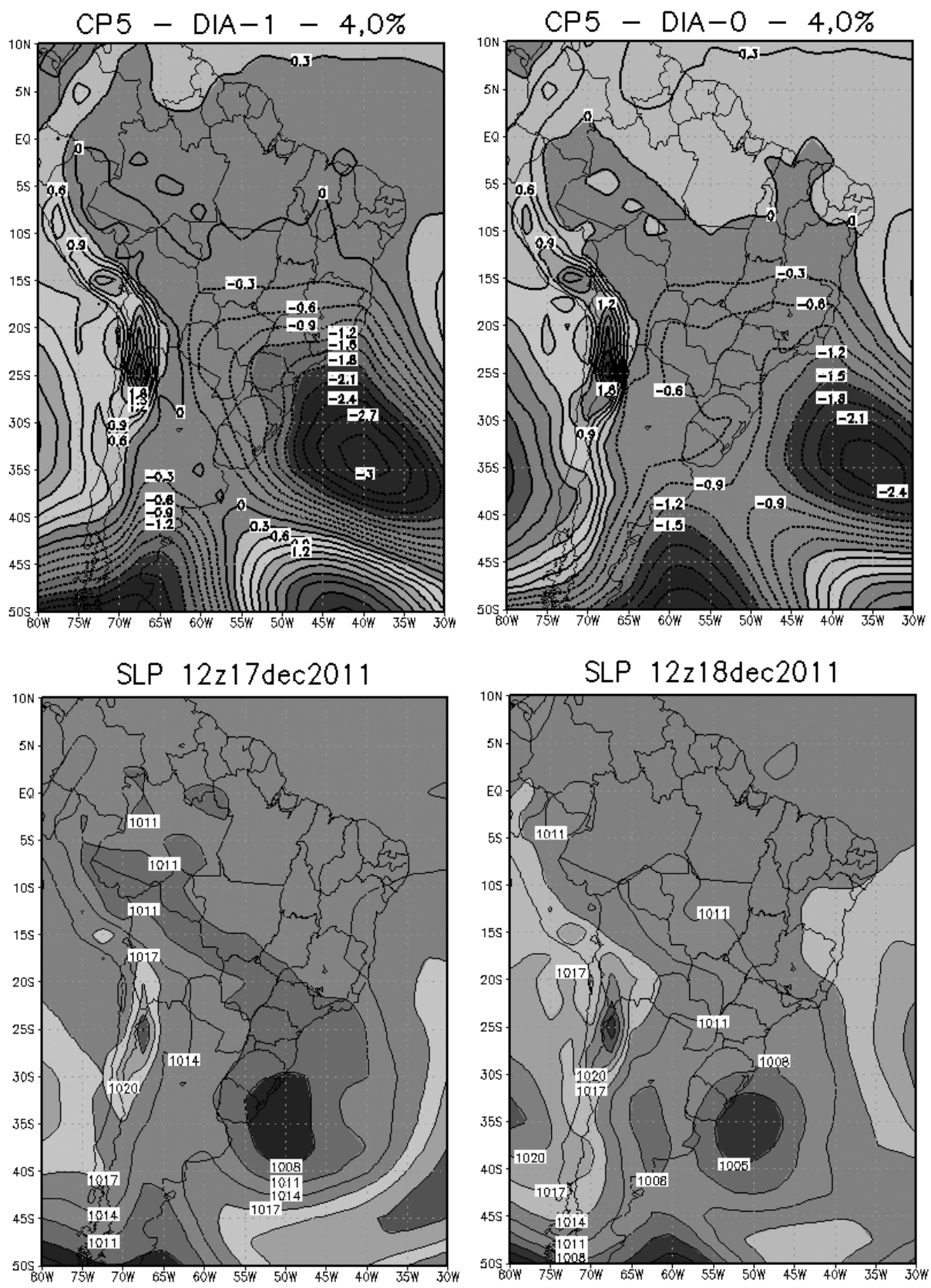

Figura 6 - Quinta Sequência de Componentes Principais (PSP4PSP5-Sup) (parte superior) e um caso de pressão em superfície altamente correlacionado $(16 / 12 / 11-18 / 12 / 11)$ (parte inferior). 
foram encontrados por Moura e Escobar (2013), que fizeram uma classificação sinótica associada com estes eventos.

O quinto PSP (Figura 6, parte superior), PSP5-Sup, também é um modelo de circulação em superfície pouco frequente durante o mês de dezembro, já que representa apenas $4 \%$ da variância total dos dados. Apesar disto, é um padrão sinótico que pode estar associado a eventos de chuva intensa em parte das Regiões Sul e Sudeste do Brasil. Este modelo apresenta, no dia -2, uma ampla área de baixa pressão centrada aproximadamente em $47^{\circ} \mathrm{W}, 32^{\circ} \mathrm{S}$ e um anticiclone ao sul deste sistema, localizado em $50^{\circ} \mathrm{W}, 47^{\circ} \mathrm{S}$.

A Figura 6 (parte inferior) mostra uma sequência real associada com o PSP5-Sup descrito anteriormente. É possível observar um amplo ciclone de aproximadamente $1005 \mathrm{hPa}$, que no decorrer do período analisado apresenta uma situação quase-estacionária. A experiência operacional mostra que muitos destes ciclones geralmente apresentam uma estrutura vertical fria muito fraca, caracterizando-se como extratropical. Porém,
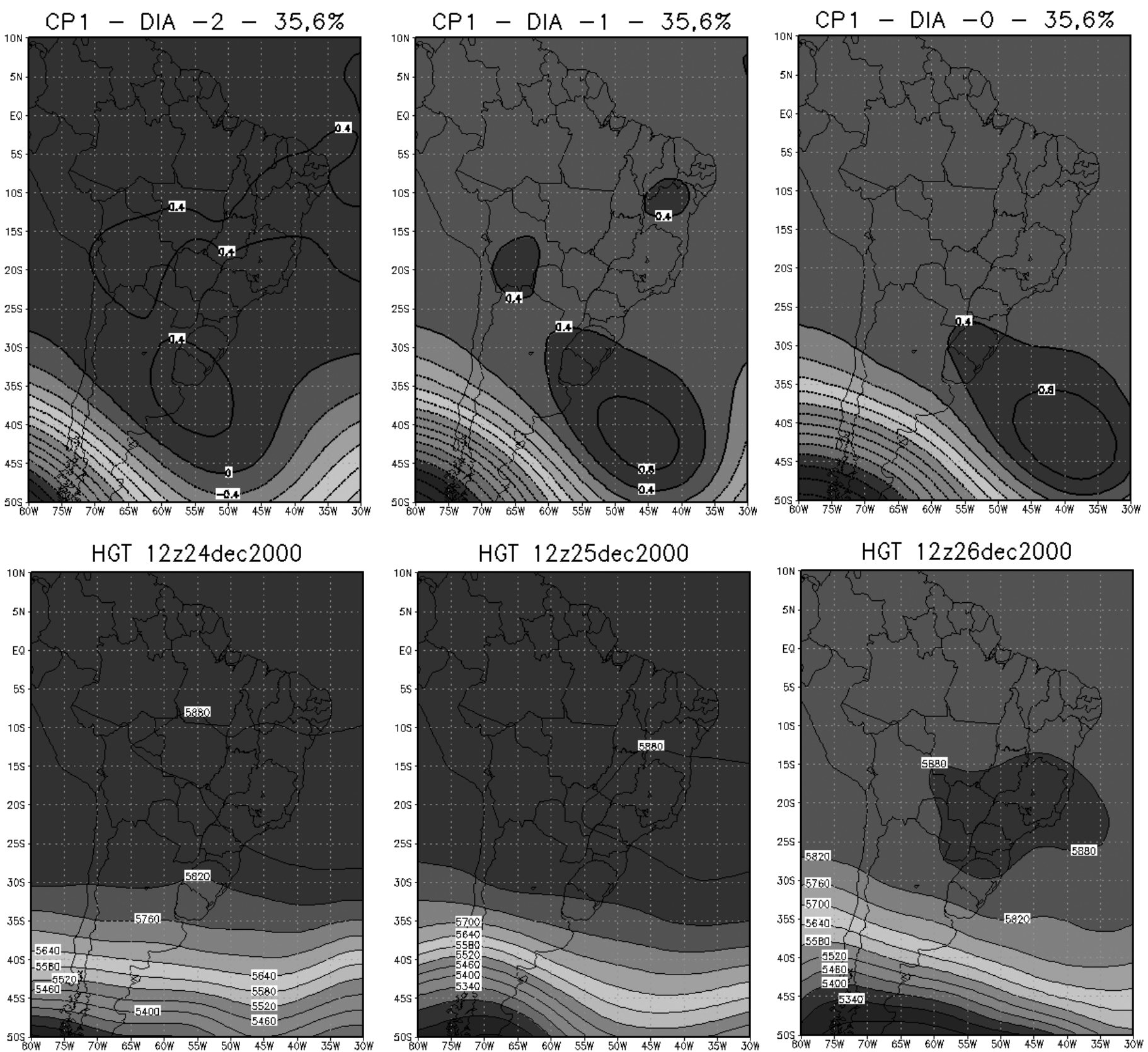

Figura 7 - Primeira Sequência de Componentes Principais (PSP1-500) (parte superior) e um caso de altura geopotencial altamente correlacionado $(24 / 12 / 00-26 / 12 / 00)$ (parte inferior). 
em algumas oportunidades apresentam um núcleo quente nas camadas mais baixas (pelo menos até $850 \mathrm{hPa}$ ) e um núcleo frio na média troposfera (aproximadamente entre 700 e 400 $\mathrm{hPa}$ ). Desta forma, estes tipos de ciclones se caracterizam como "subtropicais" (Hart, 2003). Devido à característica estacionária deste sistema de baixa pressão, o canal de umidade organizado desde a região amazônica em direção ao oceano Atlântico, persiste por vários dias podendo determinar episódios de ZCAS (Escobar e Carvalho, 2005). Desta maneira, este padrão sinótico de superfície pode estar relacionado com chuvas volumosas sobre parte do Estado de MG.

\subsubsection{Altura geopotencial em $500 \mathrm{hPa}$}

A análise da altura geopotencial em $500 \mathrm{hPa}$ é muito importante, pois representa um dos níveis mais úteis para a elaboração da previsão de tempo. Este nível representa a atmosfera média e tem a importante função de conduzir e guiar os sistemas meteorológicos que atuam em superfície. É importante ressaltar que, durante o verão, a chuva que ocorre sobre a Região Sudeste do Brasil é principalmente de tipo convectiva. Isto significa que as elevadas temperaturas e o alto teor de umidade do ar são as principais forçantes para a formação deste tipo de nuvens. $\mathrm{O}$ ambiente principalmente barotrópico faz com que esta Região apresente um clima de tipo tropical, fazendo com que as forçantes dinâmicas adquiram um papel secundário na geração de chuvas. Neste sentido, torna-se importante a divergência de altos níveis provocada pela difluência dos ventos entre $300 \mathrm{hPa}$ e $200 \mathrm{hPa}$, favorecendo o aumento da convergência de massa em superfície. Por isso, nesta época do ano, o campo de altura geopotencial em $500 \mathrm{hPa}$ quase nunca apresenta gradiente significativo sobre a Região Sudeste do Brasil, exceto em situações específicas relacionadas com sistemas frontais ou cavados baroclínicos. Esta característica do campo de altura geopotencial em $500 \mathrm{hPa}$ faz com que haja pouca variabilidade espacial deste campo em relação ao campo de pressão em superfície. Por isso, a aplicação da ACP ao campo de altura geopotencial em $500 \mathrm{hPa}$ deve apresentar uma

Tabela 2 - Porcentagens da variância explicada e da variância acumulada pelos quatro primeiros PSP de $500 \mathrm{hPa}$ durante o mês de dezembro.

\begin{tabular}{|l|c|}
\hline CPs & VAR. (\%) / CUM. VAR (\%) \\
\hline 1 & $35,6 / 35,6$ \\
\hline 2 & $34,6 / 70,2$ \\
\hline 3 & $22,4 / 92,6$ \\
\hline 4 & $1,4 / 94$ \\
\hline
\end{tabular}

quantidade menor de componentes principais do que as variáveis em superfície para representar a variância total dos dados.

A aplicação da ACP identificou quatro padrões de circulação em altitude que explicaram $94 \%$ da variância total. A Tabela 2 mostra as porcentagens da variância explicada e porcentagens da variância acumulada pelas componentes. Nota-se que os três primeiros PSP representam mais dos $92 \%$ da variância total e o PSP4 representa apenas 1,4\%. Isto significa que o PSP4 representa um modelo conceitual pouco frequente durante o mês de dezembro.

O primeiro PSP (Figura 7, parte superior), PSP1-500, mostra uma configuração de altura geopotencial, representada pela atuação de um sistema de alta da pressão centrado principalmente no oceano Atlântico. No decorrer do período estudado, este sistema apresenta um lento deslocamento para leste. Atrás deste sistema, principalmente ao sul do paralelo $40^{\circ}$, observa-se um intenso cavado que atua principalmente no sul do continente. Este padrão de circulação é bastante frequente durante o mês de dezembro, onde o ASAS encontra-se mais intenso e localizado mais ao sul, impedindo que os transientes avancem para latitudes mais baixas. A experiência operacional também mostra que, este tipo de configuração em $500 \mathrm{hPa}$, pode estar associado à presença de cavados e/ou de sistemas frontais fracos ou em frontólise, localizados no oceano na altura do Sudeste do Brasil. Estes sistemas apresentam pouco gradiente de temperatura e são mais rasos com pouca propagação para altitudes maiores. Desta forma não conseguem refletir no campo de altura geopotencial em $500 \mathrm{hPa}$.

O segundo PSP (Figura 8, parte superior), PSP2-500, mostra um padrão de circulação associado ao deslocamento de um cavado frontal que chega ao sul da Região Sudeste do Brasil no dia 0 . Atrás deste cavado frontal nota-se a presença de um anticiclone que se desloca de forma predominantemente zonal. A Figura 8 (parte inferior) mostra um caso real correlacionado com este PSP-500. É possível observar o aumento da amplitude do cavado, favorecendo o avanço da frente fria até latitudes mais baixas. Desta maneira o sistema frontal frio consegue atingir a faixa leste do Estado de SP e, em certas ocasiões, organizar um canal de umidade no interior da Região Sudeste. Desta maneira as chuvas conseguem atingir boa parte do centro-sul de MG. Entre os paralelos $10^{\circ} \mathrm{S}$ e $25^{\circ} \mathrm{S}$, observa-se uma ampla área de alta pressão, cobrindo boa parte da porção central e norte de MG. Isto contribui para inibir o mecanismo de levantamento de origem dinâmica sobre esta parte do Estado mineiro.

O terceiro PSP (Figura 9, acima), PSP3-500, também apresenta um modelo de circulação associado ao deslocamento de um cavado frontal, porém mostrando um sistema mais intenso e amplificado em relação ao PSP2-500. O caso real observado, altamente correlacionado com este modelo (Figura 9, abaixo) mostra o cavado frontal avançando desde o sul do continente 

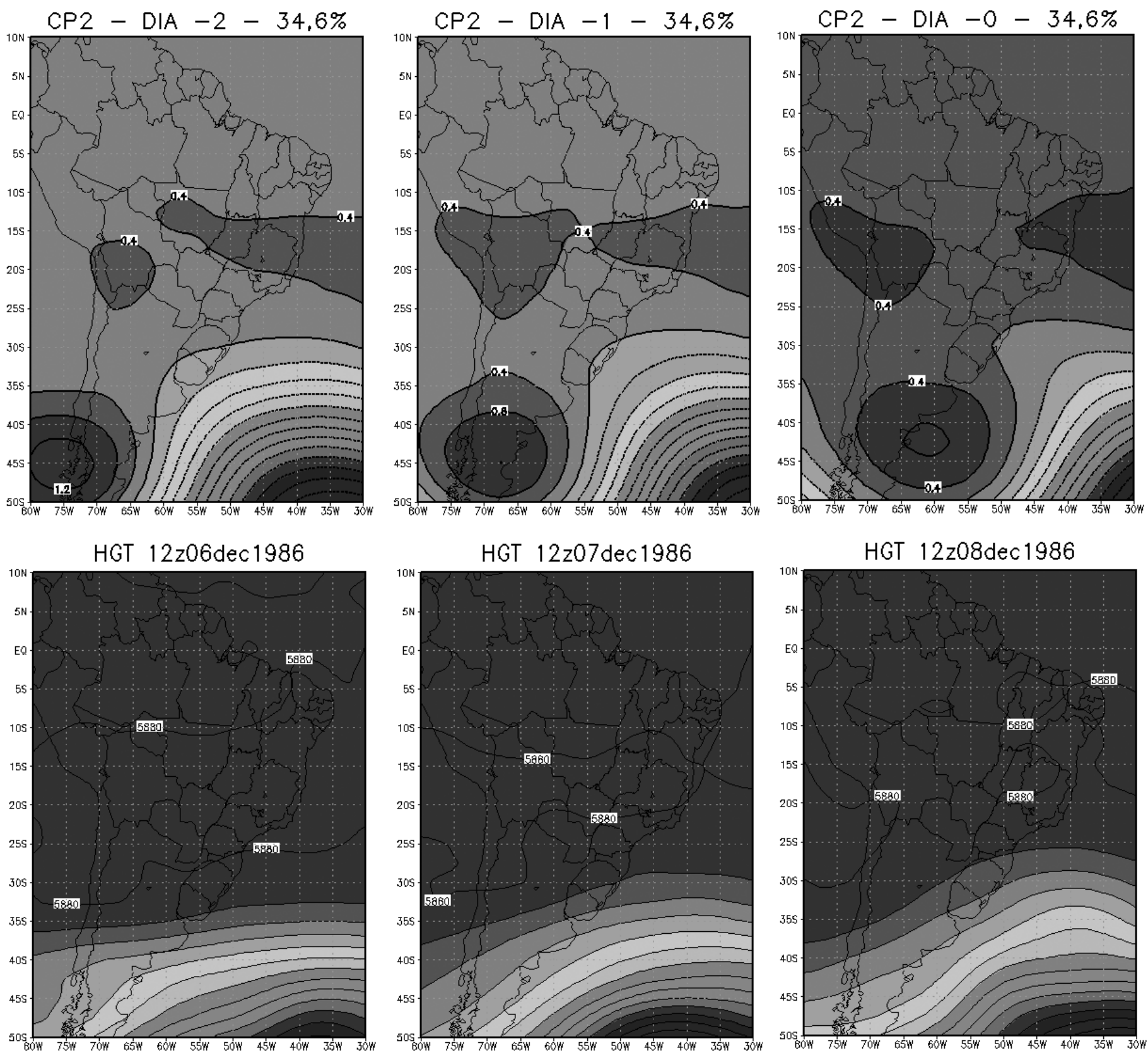

Figura 8 - Segunda Sequência de Componentes Principais (PSP2-500) (parte superior) e um caso de altura geopotencial altamente correlacionado (06/12/86 - 08/12/86) (parte inferior).

sul-americano em direção ao centro-sul do Brasil. Este cavado frontal apresenta uma forte curvatura ciclônica o que favorece a intensificação da advecção de vorticidade ciclônica sobre o centro-norte da Argentina, Paraguai, Uruguai e grande parte da Região Sul do Brasil. A frente fria associada com este intenso cavado provavelmente apresenta uma maior intensidade, porém restrito apenas às latitudes mais altas.

O quarto PSP (Figura 10, parte superior), PSP4-500, representa um modelo de circulação pouco frequente já que representa apenas $1,4 \%$ da variância total dos dados. Este padrão de circulação em $500 \mathrm{hPa}$ apresenta uma configuração de tipo dipolo, com um vórtice ciclônico centrado no oceano Atlântico, aproximadamente em $50^{\circ} \mathrm{W}, 35^{\circ} \mathrm{S}$ e um anticiclone localizada ao sul deste sistema vórtice ciclônico. O caso de real observado (Figura 10, parte inferior), mostra um vórtice ciclônico localizado a leste do RS que se mantém estacionário ao longo do período analisado. $\mathrm{O}$ ar frio associado com este sistema dinâmico contribui para aumentar a instabilidade do ar sobre toda 

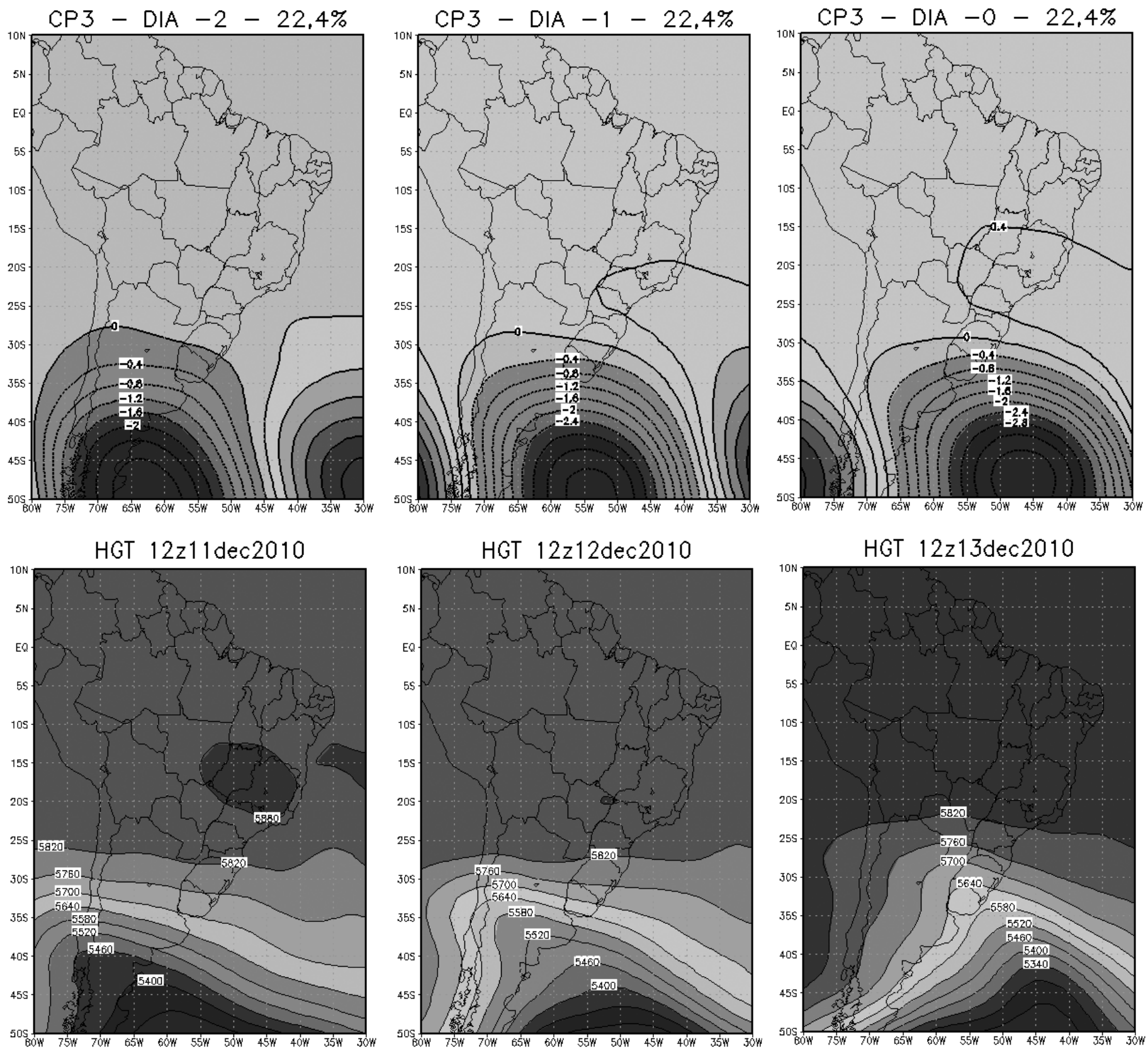

Figura 9 - Terceira Sequência de Componentes Principais (PSP3-500) (parte superior) e um caso de altura geopotencial altamente correlacionado $(11 / 12 / 11-13 / 12 / 11)$ (parte inferior).

a área de atuação. Por outro lado, a advecção de vorticicidade ciclônica resultante da presença do cavado associado a este vórtice contribui para diminuir a pressão em superfície, o que favorece o aumento da convergência de massa neste nível.

A aplicação da ACP ao campo de altura geopotencial em $300 \mathrm{hPa}$ (Figuras não mostradas) apresentou resultados similares aos obtidos no campo de $500 \mathrm{hPa}$. O segundo PSP associado com o avanço de uma frente fria até o leste de SP permitiu identificar a presença do Vórtice Ciclônico do Nordeste
(VCN)(Kousky e Gan, 1981) no leste desta Região, sendo este um sistema típico do verão (Vera et al., 2006).

\subsubsection{Relação entre superfície e altura geopotencial em $500 \mathrm{hPa}$}

Com o objetivo de analisar a estrutura vertical da circulação atmosférica associada ao mês de dezembro, foram relacionados os campos altura geopotencial em $500 \mathrm{hPa}$ 

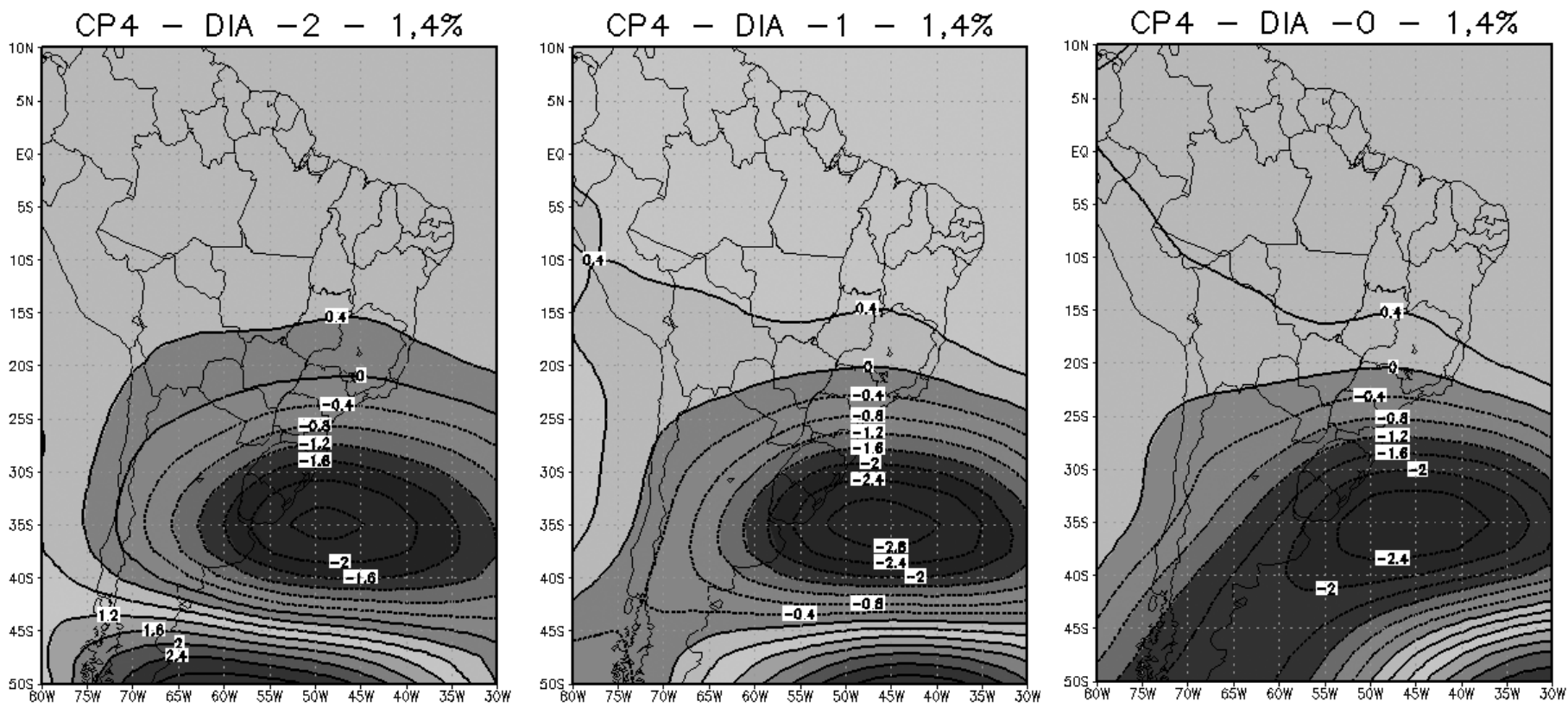

HGT 12z16dec2011
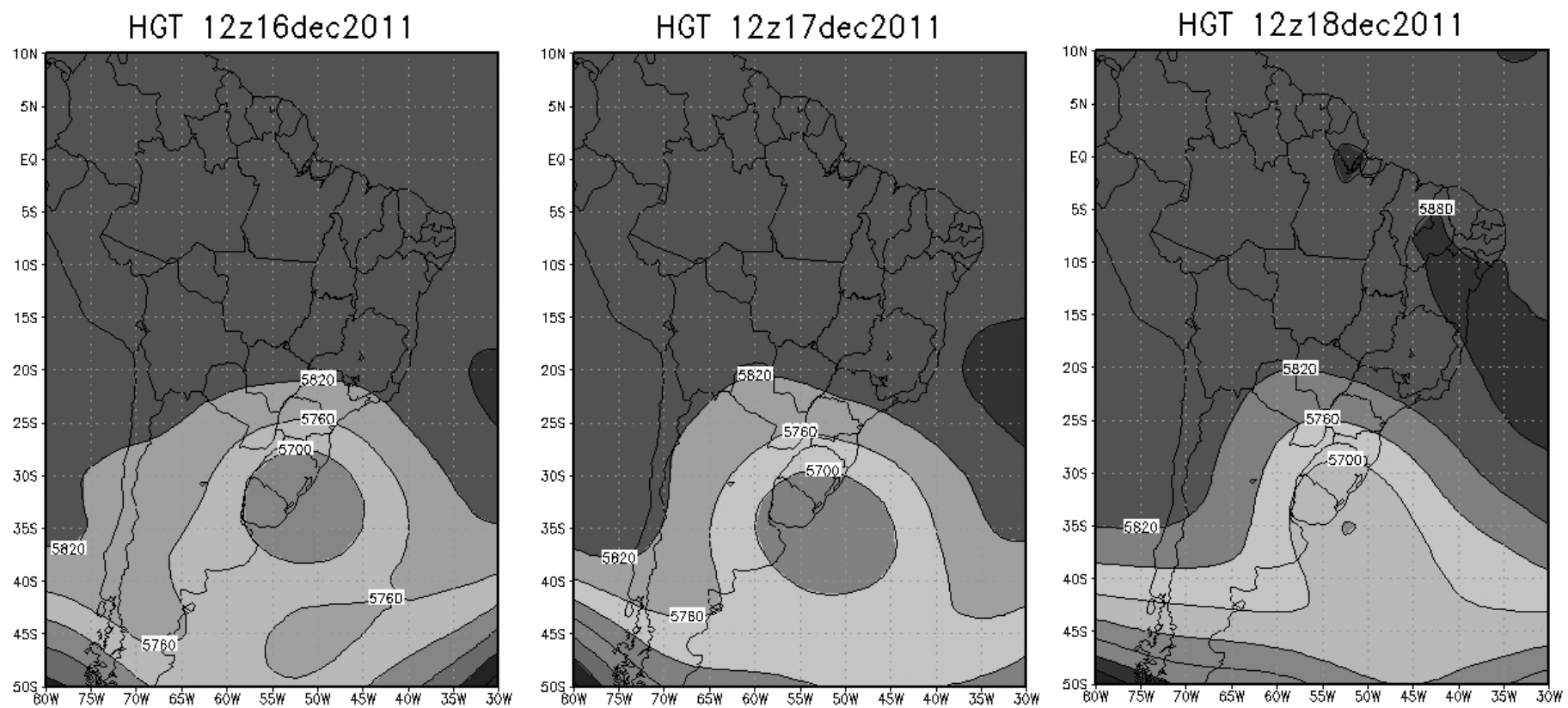

Figura 10 - Quarta Sequência de Componentes Principais (PSP4-500) (parte superior) e um caso de altura geopotencial correlacionado (16/12/11 - 18/12/11)(parte inferior).

com aqueles de superfície. Essa relação foi feita através da comparação visual das séries de factor loadings correspondentes a cada PSP de superfície e $500 \mathrm{hPa}$. A partir desta análise, foram determinadas três relações: o primeiro padrão de sequência principal de superfície (PSP1-Sup) (Figura 2) com o primeiro padrão de sequência principal de $500 \mathrm{hPa}$ (PSP1-500) (Figura 7), o segundo padrão de sequência principal (PSP2-Sup) (Figura3) com o segundo padrão de sequência principal de $500 \mathrm{hPa}$ (PSP2500) (Figura 8) e o quinto padrão de sequência principal (PSP5-
Sup) (Figura 6) com o quarto padrão de sequência principal de $500 \mathrm{hPa}$ (PSP4-500) (Figura 10).

\section{i) PSP1-Sup em superfície com PSP1-500 em 500 hPa}

Este modelo de circulação em superfície mostra a presença do ASAS aproximadamente em $40^{\circ} \mathrm{S}, 40^{\circ} \mathrm{W}$, a atuação de um cavado frontal se estendendo desde o oceano Atlântico até a Patagônia argentina e a presença da BNOA a leste dos 
Andes. Nota-se que, no decorrer do período analisado, a BNOA se acopla com a frente fria que está na Argentina, adquirindo em consequência maior intensidade.

Em $500 \mathrm{hPa}$ é possível observar um reflexo do padrão descrito em superfície, ou seja a presença de um cavado frontal na Patagônica argentina e a presença de um anticiclone localizado principalmente sobre o oceano com lento deslocamento para leste/sudeste no decorrer do período de estudo. Com este padrão de circulação em $500 \mathrm{hPa}$, os sistemas frontais ficam mais restritos a latitudes mais altas, não podendo atingir áreas da Região Sudeste do Brasil. Em função desta característica sazonal, o campo de altura geopotencial em $500 \mathrm{hPa}$ sobre áreas subtropicais e tropicais não apresenta variações significativas. A Figura 7 (parte inferior) confirma esta inferência, já que o campo de altura geopotencial não mostra nenhum gradiente sobre latitudes ao norte do paralelo $25^{\circ} \mathrm{S}$.

\section{ii) PSP2-Sup em superfície com PSP2-500 em 500 hPa}

Este modelo de circulação em superfície e em $500 \mathrm{hPa}$ está associado ao deslocamento de uma frente fria que avança desde o Sul até o Sudeste do Brasil, atingindo em média a faixa leste de SP, RJ e o extremo sul de MG. Em certas ocasiões, este sistema frontal permanece estacionário sobre o Sudeste por vários dias determinando um episódio de ZCAS (Escobar e Carvalho, 2005). Nestes casos de ZCAS a instabilidade atmosférica provocada pela frente pode atingir boa parte de MG e em consequência gerar episódios de chuva intensa sobre algumas localidades deste Estado.

\section{iii) PSP5-Sup em superfície com PSP4-500 em 500 hPa}

Como foi mencionado anteriormente este modelo de circulação é pouco frequente já que representa pouca porcentagem de variância explicada.

Nota-se a presença de um intenso e abrangente sistema de baixa pressão sobre superfície e $500 \mathrm{hPa}$, centrado sobre o oceano, que se desloca de forma muito lenta para leste. Este intenso sistema de baixa pressão, tanto em superfície quanto em altitude, penetra inclusive sobre áreas continentais, provocando convergência de massa na camada baixa da atmosfera, favorecendo o mecanismo de levantamento. Nota-se que este sistema também contribui para advectar ar quente e úmido da região amazônica, favorecendo também a instabilização do ar sobre grande parte da Região Sudeste do Brasil. A baixa em superfície e o vórtice ciclônico em $500 \mathrm{hPa}$ encontram-se praticamente em fase, determinando um padrão de circulação com estrutura barotrópica equivalente que também pode contribuir para organizar episódios de ZCAS e provocar chuvas intensas sobre boa parte do Estado de MG.

\subsection{Padrões sinóticos predominantes durante o mês de dezembro de 2011}

Com o intuito de identificar o padrão de circulação predominante ao longo do mês de dezembro de 2011 foi calculada a variância explicada por cada PSP ao longo dos 26 anos analisados. A Figura 11 mostra a variância explicada pelos três primeiros PSP de superfície ao longo dos 26 anos analisados. Em termos gerais, pode-se observar que ao longo de todo o período analisado, os PSP1-Sup e PSP2-Sup representam maior porcentagem de variância em relação ao PSP3-Sup. Porém, é possível observar uma ampla variabilidade interanual da variância explicada por cada PSP.

Nota-se que, durante dezembro de 2011, o PS3-Sup foi o modelo de circulação em superfície que teve a maior contribuição $(1,13 \%)$ na variância total correspondente a esse ano. Por outro lado, os PSP1-Sup e PSP2-Sup tiveram pouca contribuição $(0,5 \%$ e $0,4 \%$, respectivamente). Observa-se também (Figura 11), que o PSP3-Sup mostrou a maior porcentagem de variância dos últimos 26 anos. Isto significa que o modelo de circulação em superfície que predominou durante o mês de dezembro de 2011 esteve associado com a presença de uma ampla área de baixa pressão que dominou boa parte do centro-sul do Brasil. Este amplo sistema de baixa pressão apresentava o núcleo mais intenso sobre o interior do continente, entre o norte da Argentina, Bolívia e Mato Grosso do Sul (MS) e se estendia em direção ao oceano Atlântico. Sobre latitudes mais altas, ao sul do paralelo $40^{\circ} \mathrm{S}$ e aproximadamente entre $60^{\circ} \mathrm{W}$ e $30^{\circ} \mathrm{W}$, observou-se a atuação de um sistema de alta pressão. Ambos os sistemas de baixa e alta pressão determinam um índice de circulação zonal baixo, impedindo que os transientes avancem para latitudes mais baixas. A Figura 4 mostra o PSP3-Sup e um caso altamente correlacionado.

As análises diárias das cartas de superfície elaboradas pelo Grupo de Previsão de Tempo (GPT) do CPTEC mostram que durante o mês de dezembro de 2011 houve quatro episódios de ZCAS (2-5; 9-12; 15-21 e 26-30), sendo que durante os períodos 3-7, 12-16 e 25-27 a situação sinótica predominante mostrou um campo de circulação similar ao PSP3-Sup. Isto significa que este PSP3-Sup tem uma relação direta com a ocorrência de ZCAS.

A Figura 12 mostra o campo médio de pressão e o campo médio de anomalia de pressão correspondente ao mês de dezembro de 2011. Nota-se a presença do ASAS com um valor central de $1014 \mathrm{hPa}$ localizado aproximadamente em $45^{\circ} \mathrm{W}$ e $42^{\circ} \mathrm{S}$. O campo de anomalia de pressão encontra-se localizado um pouco mais ao sul do máximo de pressão, indicando que este sistema foi mais intenso, persistente e posicionado mais ao sul em relação à climatologia. Nota-se também uma ampla área de baixa pressão relativa, representada pela presença de dois 


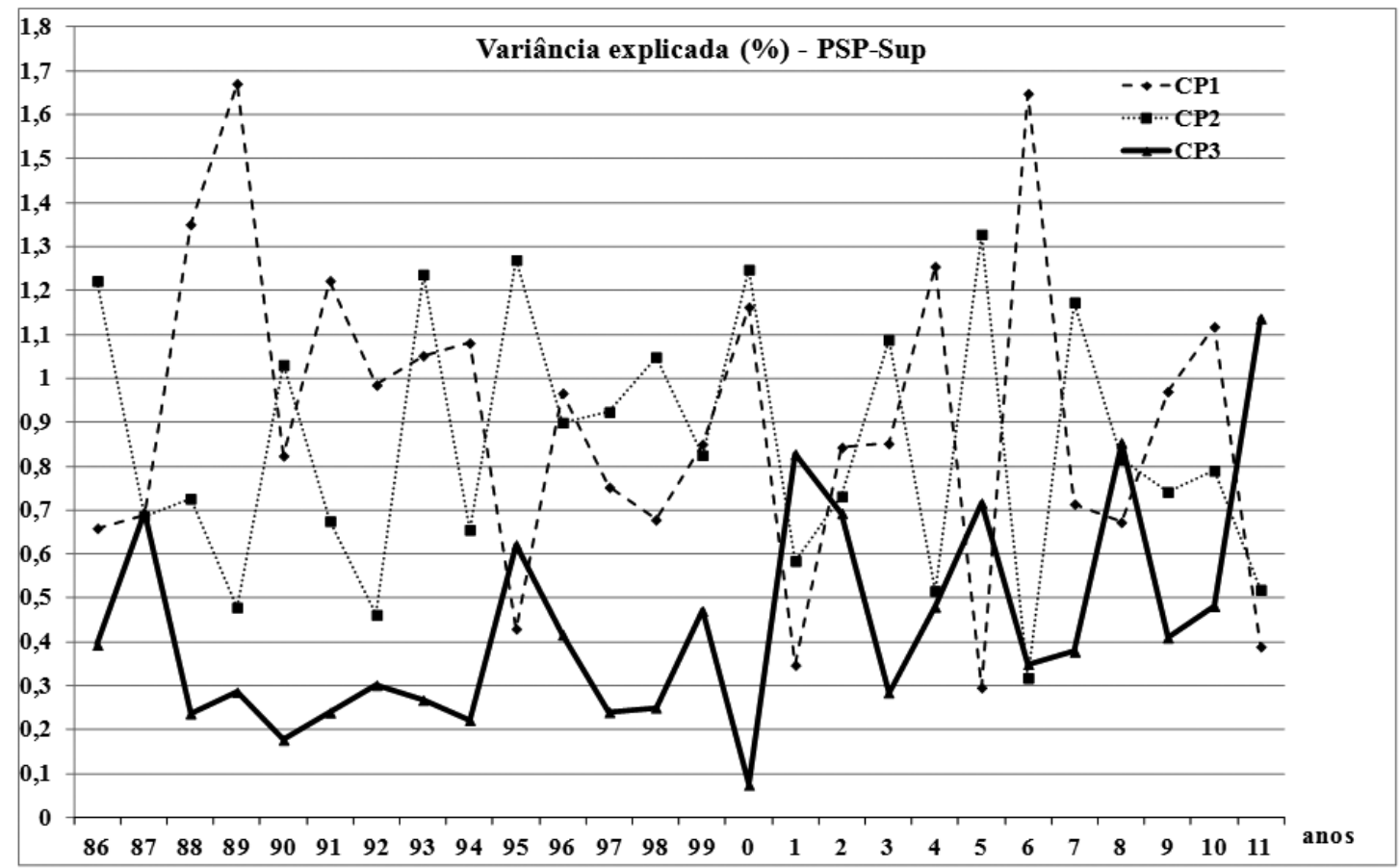

Figura 11 - Variância explicada pelos três primeiros PSP de superfície ao longo dos 26 anos analisados.

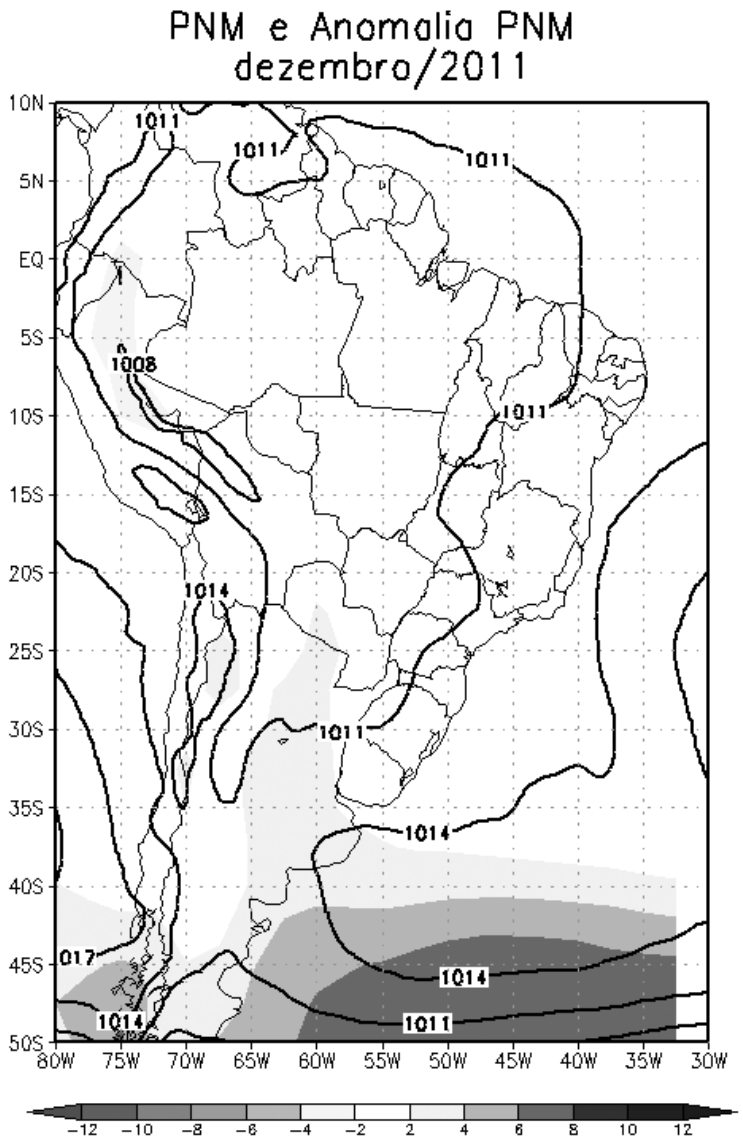

Figura 12 - Campo médio mensal (linha contínua) e anomalia média mensal (sombreado) da pressão ao nível do mar correspondente ao mês de dezembro de 2011 . cavados invertidos de onda relativamente curta se estendendo desde o interior do RS e SP, respectivamente, em direção ao oceano Atlântico. Este sistema de baixa pressão em superfície reflete os frequentes cavados e/ou ciclones que atuaram sobre essa região. Este campo médio de pressão em superfície é semelhante ao modelo de circulação em superfície representado pelo PSP3-Sup (vide Figura 4). Desta forma pode-se concluir que este modelo de circulação em superfície teve uma estreita relação com a ocorrência de chuvas anômalas sobre o Sudeste do Brasil, principalmente sobre o Estado de MG.

A análise da variabilidade interanual da variância explicada pelos três primeiros PSP de $500 \mathrm{hPa}$ ao longo dos 26 anos analisados (Figura 13) não permite identificar um padrão de circulação em particular que tenha se destacado durante o mês de dezembro de 2011. No entanto, a análise da variância explicada pelo PSP4-500 (Figura 13) mostra um pequeno máximo absoluto durante o dezembro de 2011, nunca observado ao longo destes últimos 26 anos. Ressalta-se que este PSP4500 (vide Figura 9) representa apenas o 1,4\%, da variância total dos dados, isto significa que este padrão de circulação em $500 \mathrm{hPa}$ é pouco frequente durante o mês de dezembro. No entanto, apesar de sua pouca representatividade, este padrão de circulação teve uma participação importante em dezembro de 2011. A circulação atmosférica associada com este modelo de altitude apresentava um intenso sistema de baixa pressão, localizado preferencialmente no oceano Atlântico, porém devido a sua ampla abrangência, penetrava também sobre áreas 


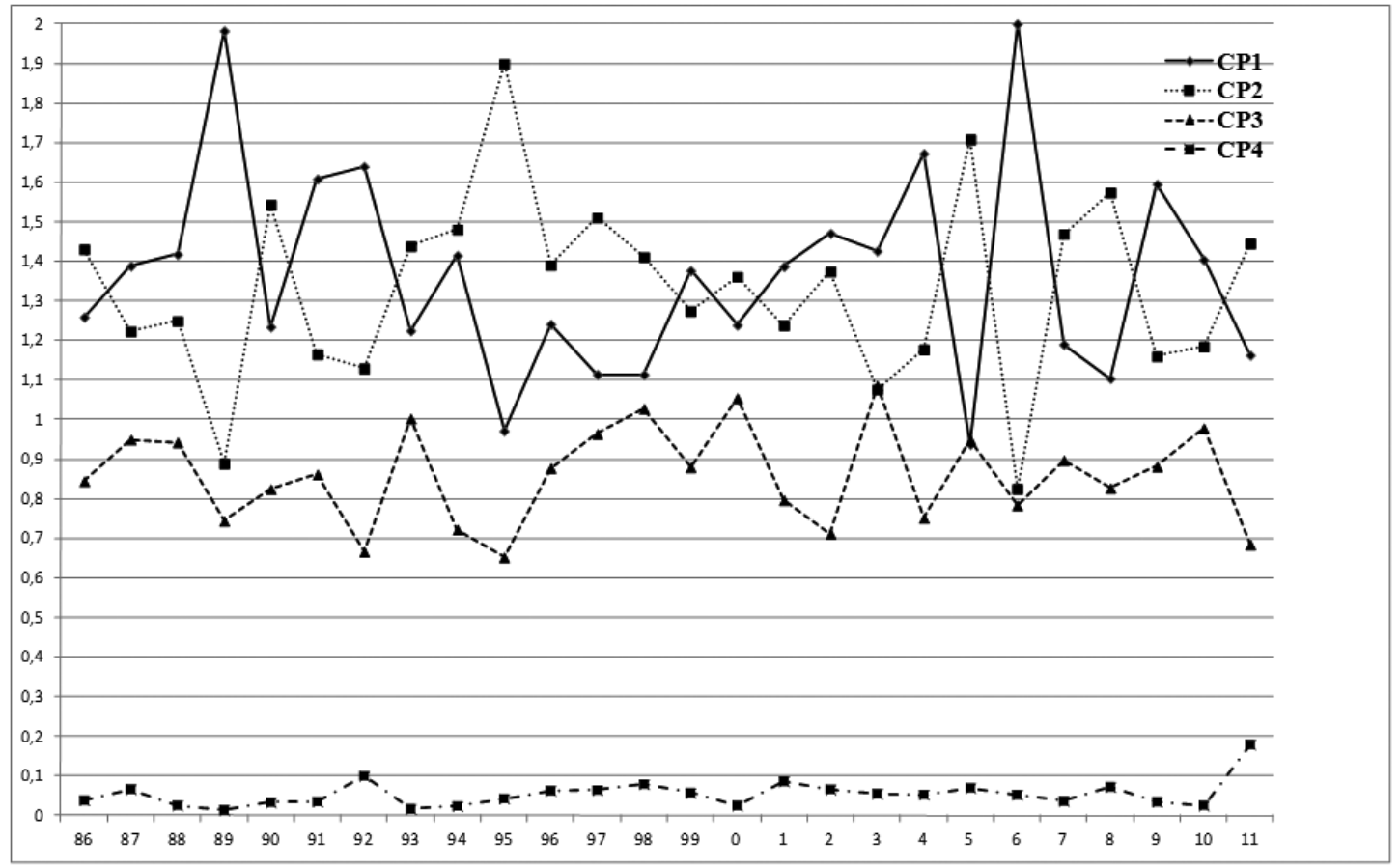

Figura 13 - Variância explicada pelos PSP de $500 \mathrm{hPa}$ ao longo dos 26 anos analisados.

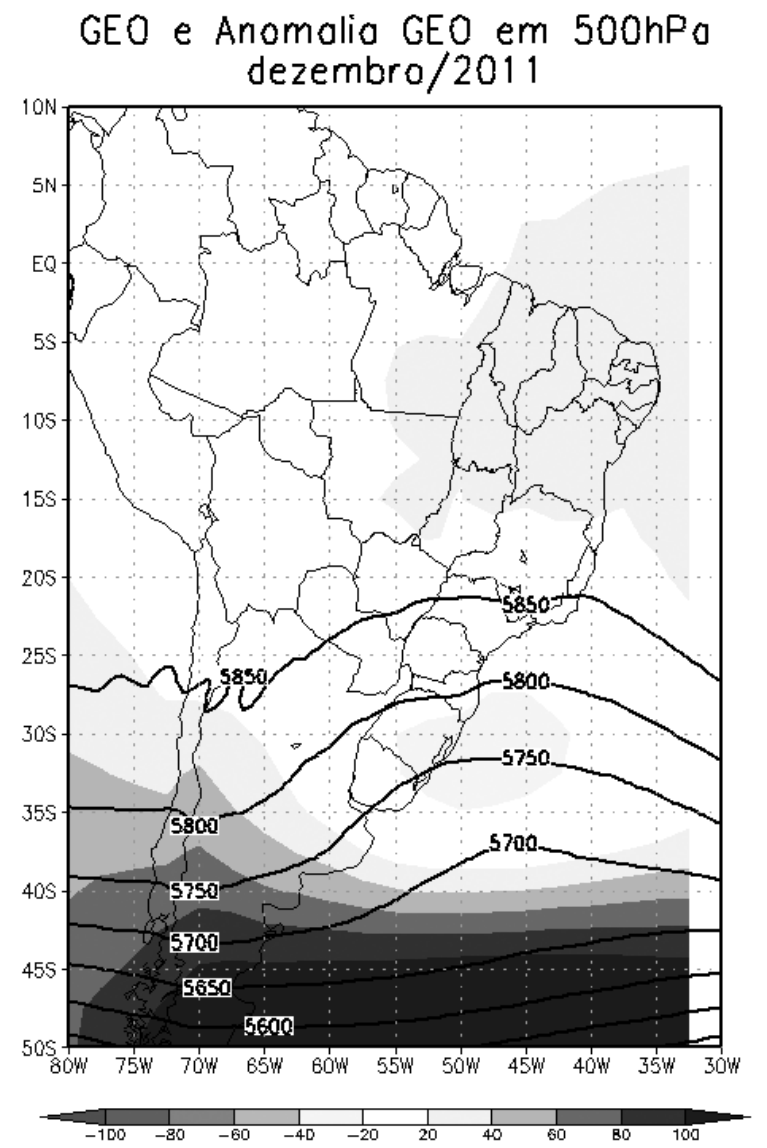

Figura 14 - Campo médio mensal (linha contínua) e anomalia média mensal (sombreado) da altura geopotencial em $500 \mathrm{hPa}$ correspondente ao mês de dezembro de 2011. continentais em especial sobre grande parte da Região Sul e parte da Região Sudeste do Brasil. Este sistema dinâmico frio contribuiu para instabilizar ainda mais a coluna atmosférica, já que durante esta época do ano nota-se um predomínio de uma massa ar quente e úmida.

As análises diárias das cartas de altura geopotencial em $500 \mathrm{hPa}$ elaboradas pelo Grupo de Previsão de Tempo (GPT) do CPTEC mostram que durante o mês de dezembro de 2011 houve aproximadamente uma semana, entre os dias 13 e 20 onde a circulação atmosférica neste nível foi similar ao PSP4500. Durante este período o GPT identificou um evento de ZCAS entre os dias 15 e 20. Isto significa que este padrão de circulação em $500 \mathrm{hPa}$ também tem uma relação estreita com a ocorrência de ZCAS.

A Figura 14 mostra o campo médio de altura geopotencial e o campo médio de anomalia de altura geopotencial em $500 \mathrm{hPa}$ correspondente ao mês de dezembro de 2011. Nota-se a presença de um cavado anômalo sobre parte do Sul e Sudeste, cujo eixo se estende meridionalmente desde o oceano Atlântico em direção ao continente. Na faixa continental e oceânica, ao sul do paralelo $40^{\circ} \mathrm{S}$, observa-se um máximo de anomalia de altura geopotencial, que junto ao cavado anômalo descrito anteriormente determinam uma configuração de bloqueio tipo " dipolo". Este modelo de circulação em $500 \mathrm{hPa}$ é semelhante ao representado pelo PSP4500 (vide Figura 10). Desta maneira, pode-se concluir que este padrão de circulação de altitude também teve contribuição direta na intensificação das chuvas ocorridas no Estado de MG. 

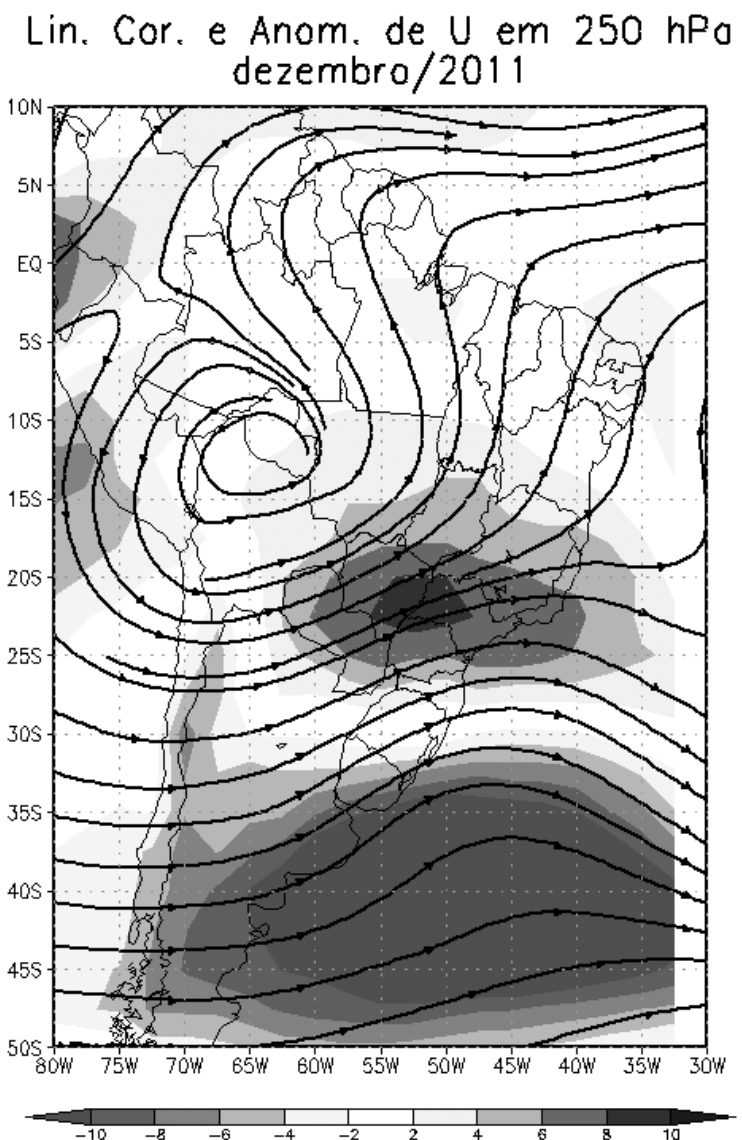

Figura 15 - Linhas de corrente e anomalia (sombreado) da componente zonal do vento em $250 \mathrm{hPa}$ correspondente ao mês de dezembro de 2011.

A Figura 15 mostra as linhas de corrente e as anomalias da componente zonal do vento no nível de $250 \mathrm{hPa}$ para o mês de dezembro de 2011. É possível observar uma configuração de circulação semelhante ao campo de $500 \mathrm{hPa}$, isto significa a presença de um cavado com eixo no oceano Atlântico, atuando sobre parte das Regiões Sul e Sudeste do Brasil. Observa-se também a presença da Alta da Bolivia e do Cavado do Nordeste, sistemas característicos da América do Sul durante o verão. $\mathrm{Na}$ região compreendida entre a borda sul da Alta da Bolívia e o cavado mencionado anteriormente apresenta um máximo de anomalia de vento zonal, o que reflete a presença do jato subtropical. A saída do jato subtropical contribui para gerar bastante difluência sobre boa parte do Estado de MG o que favorece a divergência neste nível. Este é mais um mecanismo de levantamento, vinculado diretamente com a atuação do cavado na troposfera média e alta, que favorece a convergência de massa nas camadas baixas. Assim, a divergência em altos níveis contribui para intensificar as chuvas sobre boa parte do Estado de MG.

No continente e em parte do oceano Atlântico, aproximadamente entre os paralelos $30^{\circ} \mathrm{S}$ e $45^{\circ} \mathrm{S}$, é possível observar uma amplia área com anomalias negativas da componente zonal do vento. Por outro lado, ao sul desta região e aproximadamente entre os paralelos $45^{\circ} \mathrm{S}$ e $60^{\circ} \mathrm{S}$ nota-se uma importante região com anomalias positivas da componente zonal do vento. Este padrão de circulação anômalo observado neste nível impede que os transientes consigam atingir latitudes mais baixas, ficando mais restrito a latitudes muito mais altas. Este padrão de circulação também foi observado no campo de altura geopotencial em 500 hPa (Figura 14).

\section{CONSIDERAÇÕES FINAIS E CONCLUSÕES}

A análise da variabilidade dos campos de circulação em superfície e $500 \mathrm{hPa}$, correspondente ao mês de dezembro (1986-2011), para a América do Sul, mostra que existem seis padrões principais em superfície e quatro em $500 \mathrm{hPa}$, que representam aproximadamente $73 \%$ e $94 \%$ da variância total, respectivamente.

O padrão de circulação mais frequente em superfície apresenta uma configuração similar ao campo médio climatológico. Isto é, presença da Baixa do Noroeste da Argentina (BNOA) e a atuação do ASAS centrado aproximadamente entre os paralelos $35^{\circ} \mathrm{S}$ e $40^{\circ} \mathrm{S}$.

A borda ocidental do ASAS contribui para inibir os mecanismos dinâmicos de levantamento e para advectar ar quente e úmido mediante a circulação de quadrante norte e nordeste sobre boa parte do Sudeste. Portanto, este padrão de circulação pode estar associado com chuva sobre o Sudeste do Brasil principalmente pela combinação das elevadas temperaturas com o alto teor de umidade do ar e a divergência em níveis altos da atmosfera. O segundo padrão de circulação mais frequente mostra o deslocamento de um sistema frontal pelo Sul e parte da Região Sudeste do Brasil. Este padrão de circulação consegue atingir o leste de SP, RJ e o sul de MG, podendo provocar episódios de chuva intensa sobre grande parte destes Estados. O terceiro e quinto padrão de circulação estão associados com uma configuração de bloqueio tipo "dipolo" sobre o oceano Atlântico, determinado por um anticiclone bloqueante localizado aproximadamente em torno de $50^{\circ} \mathrm{W}$, $45^{\circ} \mathrm{S}$ e por um sistema de baixa pressão posicionado ao norte do anticiclone e na altura do paralelo $30^{\circ} \mathrm{S}$. O quinto padrão é pouco frequente e mostra o bloqueio deslocado para sudeste em relação ao terceiro. A experiência operacional indica que ambos os modelos estão relacionados com a formação de ciclones extratropicais fracos ou de características subtropicais sobre o oceano que contribuem a intensificar a convergência de umidade em direção ao interior da Região Sudeste. Este modelo de circulação em superfície também pode associar-se com episódios de ZCAS, já que padrões de circulação em superfície similares foram encontrados por Escobar e Carvalho 
(2005), que fizeram uma classificação sinótica associada com estes eventos. O quarto padrão também está associado com o deslocamento de uma frente fria pelas Regiões Sul e Sudeste do Brasil. Porém, o anticiclone pós-frontal encontra-se mais intenso e mais ao sul em relação ao segundo padrão. Este quarto padrão de circulação em superfície é menos frequente durante o verão, porém pode estar associado com episódios de chuva intensa na região metropolitana do RJ (Moura e Escobar, 2013)

O padrão de circulação mais frequente em $500 \mathrm{hPa}$ está associado com uma crista localizada no oceano Atlântico Sul que se mantém praticamente estacionária ao longo do período. Por outro lado, sobre o centro-sul do continente sul-americano, nota-se a atuação de um cavado, que reflete a posição média dos sistemas frontais nesta época do ano. Este modelo de circulação se associa com o padrão de circulação mais frequente em superfície, refletindo neste nível os principais sistemas sinóticos. Devido a este modelo de circulação mostrar uma estrutura barotrópica para grande parte do Brasil, sua influência dinâmica em relação à geração de eventos de chuva sobre o Sudeste do Brasil é muito pequena.

O segundo padrão de circulação está relacionado com o deslocamento de um cavado frontal, principalmente pelo oceano, atingindo as Regiões Sul e Sudeste. Nota-se um intenso anticiclone localizado atrás do cavado, refletindo o anticiclone pós-frontal de superfície. Este modelo de circulação está relacionado com o segundo padrão de circulação em superfície, que mostra o deslocamento de uma frente fria. O terceiro padrão também está relacionado com o deslocamento de um cavado frontal desde o sul do continente até o sul da Região Sudeste. Porém, nota-se que este cavado frontal é mais intenso e amplificado em relação ao segundo padrão. O quarto padrão é um modelo de circulação pouco frequente já que explica apenas o 1,4\% da variância total dos dados. Ele também mostra uma configuração de circulação de bloqueio tipo "dipolo" sobre o oceano Atlântico, relacionando-se diretamente com o quinto padrão de circulação em superfície.

A análise da variabilidade interanual da variância explicada pelos diferentes padrões de circulação de superfície e $500 \mathrm{hPa}$ permitiu identificar dois padrões de circulação predominantes causadores das precipitações anômalas ocorridas durante dezembro de 2011. Em superfície, o terceiro padrão foi o mais relevante na geração de episódios de chuvas anômalas sobre o Estado de MG, tendo a sua maior contribuição em relação aos últimos 26 anos. Este padrão sinótico de superfície teve uma estreita relação com a ocorrência de episódios de ZCAS, como foi comprovado mediante as análises das cartas de superfície elaboradas pelo Grupo de Previsão de Tempo (GPT) do CPTEC. Durante este mês foram identificados quatro episódios de ZCAS, sendo que a maioria deles estiveram relacionados com a presença de ciclones de características subtropicais sobre o oceano que contribuíram para intensificar a convergência de umidade em direção ao interior da Região Sudeste.

Em $500 \mathrm{hPa}$, o quarto padrão foi o mais importante em relação com a ocorrência de episódios de chuva intensa no Estado de MG. Apesar de ser um padrão de circulação pouco frequente durante o mês de dezembro, em 2011 ele teve a maior contribuição durante os últimos 26 anos. Isto também foi comprovado mediante as análises das cartas de $500 \mathrm{hPa}$ elaboradas pelo Grupo de Previsão de Tempo (GPT) do CPTEC. Este modelo de circulação atuou principalmente entre os dias 13 e 20, período onde foram registrados os acumulados diários de chuva mais significativos na região central de $\mathrm{MG}$, incluindo a cidade de Belo Horizonte. A presença de um intenso vórtice ciclônico em $500 \mathrm{hPa}$ contribuiu para instabilizar ainda mais a coluna atmosférica sobre parte do Estado mineiro.

Os campos médios climatológicos da pressão ao nível do mar e da altura geopotencial em $500 \mathrm{hPa}$, correspondentes ao mês de dezembro de 2011, mostraram configurações semelhantes com os padrões de circulação em superfície e $500 \mathrm{hPa}$ descritos anteriormente. Desta forma pode-se concluir que estes modelos de circulação em superfície e em $500 \mathrm{hPa}$ tiveram contribuição direta na ocorrência de anomalias positivas de precipitação sobre o Estado de MG durante o mês de dezembro de 2011.

A análise do campo médio de circulação em $250 \mathrm{hPa}$ correspondente ao mês de dezembro de 2011 mostrou um padrão semelhante ao descrito no campo de altura geopotencial em $500 \mathrm{hPa}$. Neste nível também foi possível identificar a presença do jato subtropical e sua contribuição na geração de divergência sobre boa parte de $\mathrm{MG}$, sendo este mais um fator para intensificar as chuvas sobre este Estado.

\section{REFERÊNCIAS BIBLIOGRÁFICAS}

\section{ANDRADE, K. M. Climatologia e comportamento dos} sistemas frontais sobre a América do Sul. 2005. 185 f. Dissertação (Mestrado em Meteorologia) Instituto Nacional de Pesquisas Espaciais, São José dos Campos, 2005.

ABREU, M. L. Climatologia da estação chuvosa de Minas Gerais: De Nimer (1977) à Zona de Convergência do Atlântico Sul. Revista Geonomos, v. 6, n. 2, p. 17-22, 1988

CARVAlHO V.; JONES, C.; LIEBMANN, B. The South Atlantic Convergence Zone: Persistence, Form, Extreme Precipitation and Relationships with Intraseasonal Activity . Journal of Climate, v. 17, n. 1, p. 88-108, 2004.

CATTELL, R. The scientific use of factor analysis: in Behavioral and Life Sciences. Plenum Press. New York and London, 1978. 
COMPAGNUCCI, R.; SALLES, M.A. Surface Pressure Patterns during the year over Southern South America. International Journal of Climatology, v. 17, n. 6, p. 635-653, 1997.

COMPAGNUCCI, R.; ARANEO, D. CANZIANI, P. Principal sequence pattern analysis: A new approach to classifying the evolution of atmospheric systems. International Journal of Climatology, v. 21, n. 2, p. 197-217, 2001.

ESCOBAR, G. C. J. Padrões sinóticos associados a ondas de frio na cidade de São Paulo. Revista Brasileira de Meteorologia, v. 22, n. 2, p. 241-254, 2007.

ESCOBAR, G.; BISCHOFF, S. Meteorological situations associated with significant temperature falls in Buenos Aires: an application to the daily consumption of residential natural gas. Meteorological Application, v. 6, n. 3, p. 253260, 1999.

ESCOBAR, G. C. J.; CARVALHO, C. I. Situações meteorológicas associadas a episódios da Zona de Convergência do Atlântico Sul (ZCAS). In: CONGRESSO ARGENTINO DE METEOROLOGIA, 9, 2005, Buenos Aires. Anais... Buenos Aires: Editora, 2005. 1 CD-ROM.

ESCOBAR, G. C. J.; COMPAGNUCCI, R. H.; BISCHOFF, S. A. Sequence Patterns of $1000 \mathrm{hPa}$ and $500 \mathrm{hPa}$ geopotential height fields associated with cold surges in Buenos Aires. Atmosfera, v 12, n. 2, p. 69-89, 2004.

GUIA C. V. F. Análises das características sinóticas das trajetórias dos ciclones extratropicais que atuam na América do Sul e Vizinhanças. 2010. 105 f. Dissertação (Mestrado em Meteorologia) - Instituto Nacional de Pesquisas Espaciais, São José dos Campos, 2010.

GREEN, P. Analysing Multivariate Data. The Dryden Press. Illinois, U.S.A, 519, 1978.

HARMAN, H. Modern Factor Analysis. The University of Chicago Press Chicago, IL, 1976.

HART, R.E. A cyclone phase space derived from thermal wind and thermal asymmetry. Monthly Weather Review, v. 131, p. 585-616, 2003.

HOSKINS, B. J; HODGES, K. I. A new perspective on the southern hemisphere storm tracks. Journal of Climate, v. 18, p. 4108-4129, 2005.

KALNAY, E. et al. The NCEP/NCAR 40-year reanalysis Project. Bulletin of the American Meteorological Society, v. 77, n. 3, p. 437-471, 1996.

KODAMA, Y. M. Large-scale common features of subtropical precipitation zones (the Baiu frontal zone, the spcz, and the SACZ), Part I: Characteristics of subtropical zones. Journal of the Meteorological Society, v.70, p. 813-835, 1992.

KOUSKY, V. E. Pentad outgoing longwave radiation climatology for the South American sector. Revista Brasileira de Meteorologia, n. 3, p. 217-231, 1988.
LUND, I. A. Map pattern classification by statistical methods. Journal of Applied Meteorology, v. 2, p. 56-65, 1963.

PREISENDORFER, R. W. Principal Component Analysis in Meteorology and Oceanography. Elseiver. Amsterdam, 1988.

QUADRO, M. F. de L. Estudo de Episódios de Zona de Convergência do Atlântico Sul (ZCAS) sobre a América do Sul. 1994. 123 f. Dissertação (Mestrado em Meteorologia) - Instituto Nacional de Pesquisas Espaciais, São José dos Campos, 1994.

MOREIRA, J. L. B.; ABREU, M. L. Distribuição espacial da precipitação sobre a região metropolitana de Belo Horizonte - MG e sua associação com a topografia local. In: CONGRESSO BRASILEIRO DE METEOROLOGIA, 12, 2002, Foz de Iguaçu-PR, Anais...Foz de Iguaçu, 2002. 1 CD-ROM.

REBOITA, M. S.; da Rocha, R. P.; Rosmeri, P.;Ambrizzi, T.; Sugahara, S. South Atlantic Ocean cyclogenesis climatology simulated by regional climate model (RegCM3). Climate Dynamics, 35, p. 1331-1347, 2010.

RICHMAN, M. Specification of complex modes of circulation with T-mode factor analysis. In: International Conference on Statistics and Climate, 2, 1983, Lisbon. Anais...Lisbon. National Institute of Meteorology and Geophysics, p. 511518, 1983.

RICHMAN, M. Rotation of Principal Components. Journal of Climatology, v. 6, n. 3, p. 293-335, 1986.

RICHMAN, M.; ANGEL, J.; GONG, X. Determination of Dimensionality in Eingenanalysis. In: International Meeting on Statstical Climatology, 5, 1992, Canada. Anais...p. 229-235, 1992.

SATYAMURTY, P.; NOBRE, C., SILVA DIAS, P.L. Tropics South America. In: KAROLY, D. J. (Ed.); VINCENT, D. G. (Ed.). Meteorology of the Southern Hemisphere. Boston: American Meteorological Society, 1998. Cap. 3, p. 119-139. (Meteorological Monographs, 49).

SINCLAIR, M. A. Climatology of cyclogenesis for the southern hemisphere. Monthly Weather Review, v. 123, p. 16011619, 1995.

VERA, C. et al. Toward a Unified View of the American Monsoon Systems. Journal of Climate-Special Section, v. 19, p. 4977-5000, 2006.

VIANELLO, R. L.; MAIA, L. P. G. Estudo preliminar da climatologia dinâmica do Estado de Minas Gerais. Revista Informe Agropecuário, Belo Horizonte, v. 12, n. 138, p. 6-8, 1986.

YARNAL, B. Synoptic Climatology in Environmental Analysis. Belhaven Press. London, 1993. 